\title{
Spatial and spectral variability of the outgoing thermal IR spectra from AIRS: A case study of July 2003
}

\author{
Xianglei Huang \\ Program in Atmospheric and Oceanic Sciences, Princeton University, Princeton, New Jersey, USA \\ Yuk Ling Yung \\ Division of Geological and Planetary Sciences, California Institute of Technology, Pasadena, California, USA \\ Received 19 October 2004; revised 11 March 2005; accepted 31 March 2005; published 17 June 2005.
}

[1] Here we present a survey of the spatial variability in different climate zones seen from AIRS data using the spectral EOF analysis. Over the tropical and subtropical oceans, the first principal component (PC1) is mostly due to the thermal contrast between surface and thick cold cloud tops. The second principal component (PC2) is mainly due to the spatial variation of the lower tropospheric humidity (LTH) and the low clouds. The signature of dust aerosol over the Arabian Sea and the Atlantic off the coast of North Africa in the summertime can be clearly seen in the PC2. Both the PC1 and the PC2 capture the upper tropospheric water vapor variability due to the forced orthogonality of EOFs. The third principal component (PC3) is mainly due to the spatial variation of the lower stratospheric temperature. Over the midlatitude oceans, the PC1 is still due to the thermal contrast of emission temperature. During wintertime, the PC2 is mainly due to stratospheric temperature variations. In the summer, the PC2 over the southern hemisphere is still due to stratospheric temperature variations, but in the northern hemisphere it is mainly due to the variations of the LTH and the low clouds. An exploratory study using synthetic spectra based on a NCAR CAM2 simulation shows that the model could account for the essential features in the data as well as provide an explanation of the three leading PCs. Major disagreements exist in the location of the ITCZ, the dust aerosol, and the lower stratospheric temperature.

Citation: Huang, X., and Y. L. Yung (2005), Spatial and spectral variability of the outgoing thermal IR spectra from AIRS: A case study of July 2003, J. Geophys. Res., 110, D12102, doi:10.1029/2004JD005530.

\section{Introduction}

[2] Our current understanding of hydrological cycle is still inadequate [Chahine, 1992] and the representation of hydrological cycle especially water vapor transport and clouds in climate models is still far from satisfactory. These facts significantly hinder our ability to project future climate change [Intergovernmental Panel on Climate Change, 2001]. Atmospheric Infrared Sounder (AIRS) mission was designed to improve our knowledge of hydrological processes in the atmosphere by providing measurements of atmospheric temperature and humidity, surface skin temperature and cloud properties. With these measurements, AIRS data could be used to improve numerical weather prediction and study key hydrological processes in the atmosphere [Aumann et al., 2003]. Additionally, the high resolution infrared spectra recorded by AIRS are useful in monitoring greenhouse gases such as $\mathrm{CO}_{2}, \mathrm{CH}_{4}, \mathrm{~N}_{2} \mathrm{O}$ and $\mathrm{O}_{3}$ [Engelen et al., 2004; Crevoisier et al., 2004]. The inflight calibrations have shown that the instrument performs as expected [Pagano et al., 2003; Gaiser et al., 2003] and the validation of AIRS retrieval products so far has yield

Copyright 2005 by the American Geophysical Union. 0148-0227/05/2004JD005530 satisfactory results [Fetzer et al., 2003; Hagan et al., 2004]. All these together make AIRS data valuable for climate studies.

[3] The outgoing thermal infrared spectra have high information content about the vertical profiles of atmospheric thermodynamic variables. One promising application is to use such observations to test general circulation models (GCMs) [Goody et al., 1998; Haskins et al., 1997; Huang et al., 2002]. Such tests are necessary and important in order to have confidence in the GCM predictions about future climate change. More detailed discussion about using the outgoing thermal infrared spectra to test climate models can be found in Goody et al. [1998] and Anderson et al. [2004]. Besides this application, the outgoing thermal infrared spectra can be also used for climate monitoring [Huang et al., 2000; Harries et al., 2001].

[4] In this paper, we first apply empirical orthogonal function (EOF) analysis (also known as principal component analysis, PCA) to AIRS data to characterize the spatial variability of the outgoing thermal infrared spectra over several climate zones and then interpret the spatial variability in term of climate variables. Next, we present results from a corresponding analysis of synthetic spectra based on a simulation over the same period as AIRS data using the 
NCAR (the National Center of Atmospheric Research) CAM2 (Community Atmospheric Model). The discrepancies between AIRS and simulation are identified and discussed. Our goal is to document the spatial variability of the outgoing thermal IR spectra seen by AIRS data using spectral EOF analysis, interpret the results, and demonstrate the feasibility and usefulness of directly comparing model results and observations for the spectrally resolved radiance. Previously such "model-to-satellite" comparisons used only one or two channels from narrowband radiometer aboard geostationary satellites [Morcrette, 1991; Schmetz and Vandeberg, 1994; Soden and Bretherton, 1994]. For example, Soden and Bretherton [1994] computed the narrow-band averaged radiance in the water vapor $6.3 \mu \mathrm{m}$ band (which is sensitive to the upper troposphere relative humidity) using clear-sky outputs from two GCMs, ECMWF and NCAR CCM, and compared the results with GOES cloudclearing observations. They showed that the discrepancies between the ECMWF model and the observations could be attributed to the underestimated strength of the large-scale circulation in the GCM while the discrepancies between NCAR CCM and the observations were not simply correlated with features related to the large-scale circulation. With the 2378 channels that AIRS has, much more information about temperature, humidity and even cloud vertical profiles is available for testing the performance of GCMs.

[5] Traditional satellite IR radiance data, such as broadband OLR measured by ERBS and $6.7 \mu \mathrm{m}$ narrowband radiance recorded by HIRS and GOES, are still valuable in climate studies and model evaluations because of their long records. On the other hand, the high spectral resolution and broad spectral coverage of AIRS spectra provide another useful data set for model evaluation. With AIRS, we can use thousands of channels to evaluate model instead of using a single integrated quantity like OLR or several narrowband channels. It might be possible that simulated OLR or singlechannel narrowband radiance could agree with observed due to cancellations of various errors and biases in a GCM. However, it is highly unlikely that simulated radiances based on this GCM can agree with observed ones over all AIRS channels because each channel is sensitive to physical quantities such as temperature and water vapor at different altitudes.

[6] In section 2, the spectral EOF analysis, data processing, and the NCAR CAM2 model are described. Section 3 presents the results of the analysis of AIRS data over the tropical and subtropical oceans. Section 4 presents similar results over the midlatitude oceans. The results based on NCAR CAM2 simulation are presented in section 5, followed by the discussion and summary in section 6 .

\section{Data Processing, Model and Methodology}

[7] The characteristics of AIRS instruments and our data processing procedure are summarized in section 2.1. The statistical technique to extract patterns of variability is introduced in section 2.2 and the GCM and radiation transfer models that we used to generate synthetic spectra are described in section 2.3.

\subsection{AIRS Instrument and Data Manipulation}

[8] Atmospheric Infrared Sounder (AIRS) is an infrared grating array spectrometer aboard AQUA, a sun-synchro- nous satellite [Aumann et al., 2003]. It acquires 2.9 million spectra every day with 2378 channels across three bands (3.74-4.61 $\mu \mathrm{m}, 6.20-8.22 \mu \mathrm{m}, 8.8-15.4 \mu \mathrm{m})$. The resolving power $(\lambda / \Delta \lambda)$ of AIRS is 1200 . The instrument field of view is 1.1 degree, corresponding to a footprint of $13.5 \mathrm{~km}$ on the surface. The scan angles vary from $-49^{\circ}$ to $49^{\circ}$. Global coverage can be obtained in the course of 2 days. The in-flight calibrations show that the radiometric accuracy is $<0.3 \mathrm{~K}$ for a $250 \mathrm{~K}$ brightness temperature target [Pagano et al., 2003], and the spectral accuracy is $<0.01 \Delta v(\Delta v$ is the full width at half maximum) [Gaiser et al., 2003]. AIRS provides an unprecedented data source of the outgoing thermal IR spectra with excellent calibration and good global coverage.

[9] In this study, we mainly use 16 days of AIRS level-1B calibrated radiances from July 01 to July 16,2003 . The data from January 01 to January 16, 2003, will be used occasionally to illustrate the winter/summer contrast. Sixteen days is an orbital repeat cycle for AIRS so that a uniform spatial sampling pattern can be expected within this period. We limit our study to the spectra with scan angles $(\theta$ between $\pm 5^{\circ}(1 \leq 1 / \cos \theta \leq 1.0039)$ so that all spectra can be treated as nadir-view spectra and no geometry correction is necessary. Among the 2378 AIRS frequency channels, some of them constantly suffer from the fluctuation of electronic noise (so-called "popcorn noise") and some have bad spectral response functions. To avoid these channels, only channels recommended by the AIRS team for level-2 retrieval purposes are used. Furthermore, spectra in the 3.74-4.61 $\mu \mathrm{m}$ band are excluded due to a consideration of signal-to-noise ratio (SNR). (The SNR at 3.74-4.61 $\mu \mathrm{m}$ band is smaller than other bands, mostly due to the small signals in this band. Moreover, whether 3.74-4.61 $\mu \mathrm{m}$ band is included or not, the results of the spectral EOF analysis at the other two bands are almost identical to each other. This is mostly due to the fact that radiances at 3.74-4.61 $\mathrm{m}$ band are smaller than those at the other two bands by one or two orders of magnitude.) In addition, we screen the data with a fairly strict quality control procedure to exclude bad spectra. It turns out that, on the average, 2.4 out of every thousand spectra have to be thrown out after the quality control.

[10] We divide the global surface into 3240 grid boxes, each being $4^{\circ}$ in latitude and $5^{\circ}$ in longitude. Inside each grid box, AIRS spectra collected at the ascending nodes and at the descending nodes within the 16-day period are equally weighted and averaged to obtain a mean spectrum for each grid box. Then we apply the spectral EOF analysis to these averaged spectra within a given climate zone to obtain the principal components and associated spatial patterns. The climate zones that we study are the tropical and the subtropical oceans $\left(32^{\circ} \mathrm{S}-32^{\circ} \mathrm{N}\right)$, the northern hemisphere midlatitude oceans (hereafter, NHMO) $\left(32^{\circ} \mathrm{N}-60^{\circ} \mathrm{N}\right)$ and the southern hemisphere midlatitude oceans (hereafter, SHMO) $\left(60^{\circ} \mathrm{S}-32^{\circ} \mathrm{S}\right)$. Land regions are excluded in this study because of possible complications arising from surface emissivity.

[11] Figure 1 shows, after quality control, the number of qualified spectra over each grid box of the tropics and the subtropics from July 1 to July 16,2003 . It can be seen that the sampling is very uniform for both daytime and nighttime. For daytime and nighttime together, the averaged number of spectra in each grid box is 1604 and the standard 

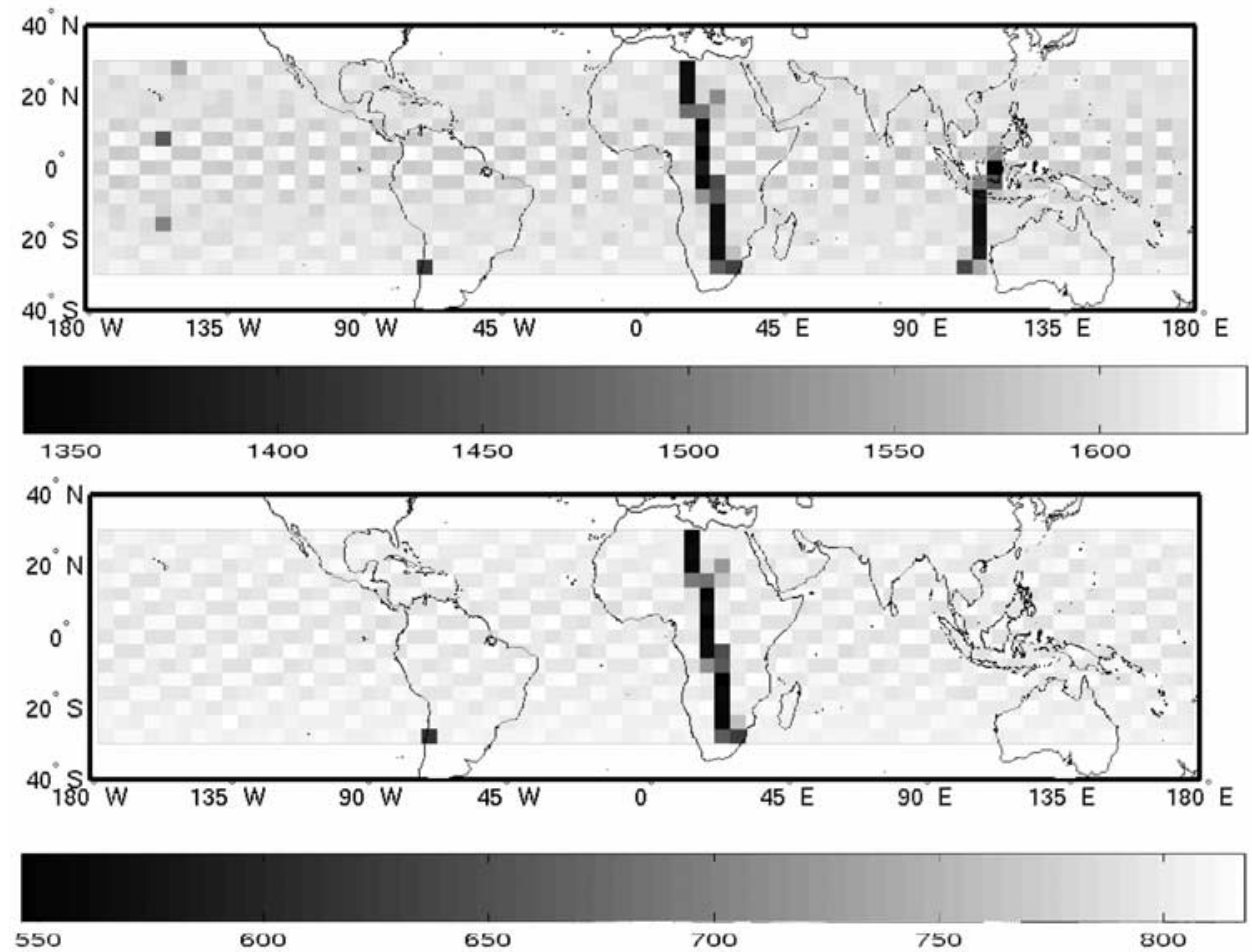

Figure 1. (top) Number of qualified both daytime and nighttime spectra used for averaging in each grid box. (bottom) Number of qualified daytime spectra used for averaging.

deviation is 37. Several grid boxes in Africa and the southern ocean west of Australia have about 250 spectra less than the mean because of the two data outage periods on July 9 due to AIRS and MODIS internal calibrations. Several grid boxes in the tropical Pacific also have about 100 spectra less than the mean because, from time to time, very cold cloud tops existed in these boxes and AIRS failed in generating correctly calibrated radiance for such scenes. If these grid boxes are excluded, the standard deviation is only 14. The samplings over the NHMO and SHMO are also very uniform. The uniform sampling pattern gives us more confidence in analyzing the spatial variability from these qualified spectra.

\subsection{Spectral EOF Analysis}

[12] The statistical technique used here to extract the spatial variability from AIRS data is principal component analysis [Hotelling, 1933] in the spectral domain, so-called spectral EOF analysis. An introduction to spectral EOF analysis can be found in Huang et al. [2003]. Following their notation, if $\mathrm{I}_{\nu}(x)$ is a set of radiances, where $\nu$ is frequency and $x$ is space. The EOFs, $\phi_{\nu}^{(i)}$, are unit eigenvectors of the covariance matrix defined by

$$
C_{\nu_{1} \nu_{2}}=\overline{\left(I_{\nu_{1}}(x)-\bar{I}_{\nu_{1}}\right)\left(I_{\nu_{2}}(x)-\bar{I}_{\nu_{2}}\right)}
$$

where the overbars represent averaging over all samples in the given set. Let $\lambda_{i}$ be the eigenvalue listed in descending order corresponding to the ith eigenvector $\phi_{\nu}^{(i)}$; then the principal component (PC) is defined as

$$
P C_{\nu}^{(i)}=\sqrt{\lambda_{i}} \phi_{\nu}^{(i)}
$$

(There is no consistent terminology for EOF analysis. The terms used by different communities could even contradict each other [Preisendorfer, 1988]. Here, we adopt these definitions to be consistent with previous works on spectral EOF studies [Haskins et al., 1999; Huang et al., 2002, 2003].) The fraction of variance explained by the ith eigenvector is $\lambda_{i} / \Sigma \lambda_{i}$. With this definition, PCs have the dimensions of radiance. The normalized expansion coefficient (EC) of the ith $\mathrm{PC}$ is

$$
E C_{i}(x)=\sum_{\nu}\left[I_{\nu}(x)-\overline{I_{\nu}(x)}\right] \phi_{\nu}^{(i)} / \sqrt{\lambda_{i}}
$$

With this definition, every EC has zero mean and unitary standard deviation. Since $x$ is a spatial coordinate, ECs can be interpreted as the spatial patterns associated with the corresponding PCs. We should note that each principal component is forced to be orthogonal to all of its predecessors. As a result, the higher-order principal components might not be amenable to simple physical interpretations because linear independence is equivalent to statistical independence only when the probability distribution of the variable is Gaussian.

\subsection{Models}

[13] The atmospheric GCM that we use is Community Atmospheric Model (CAM2) developed by NCAR. It employed a horizontal T42 spectral resolution (corresponding to $2.8^{\circ} \times 2.8^{\circ}$ transform grid) with 26 vertical levels in a hybrid coordinate. The radiation scheme is based on Collins [2001] and Collins et al. [2002]. The cloud scheme was developed by Rasch and Kristjansson [1998] and Zhang et 


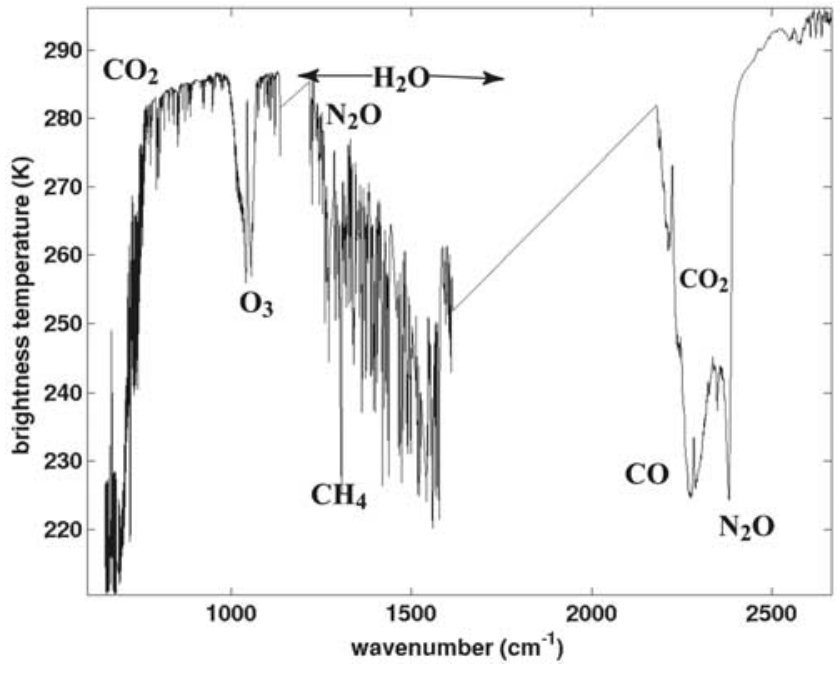

Figure 2. The mean AIRS spectrum over oceans within $32^{\circ} \mathrm{S}-32^{\circ} \mathrm{N}$ from July 1 to 16,2003 . The major absorption features are labeled.

al. [2003]. Detailed scientific description of CAM2 can be found in Collins et al. [2003].

[14] The radiative transfer model used in this study to compute synthetic spectra is the Moderate Transmittance Code (MODTRAN) v4.1 developed by Air Force Geophysical Lab [Bernstein et al., 1996; Wang et al., 1996]. It adopted a very-narrow band model approach to generate a spectrum at a fixed sampling interval of $1.0 \mathrm{~cm}^{-1}$. It was designed to be efficient, user friendly, downward compatible, and flexible in handling various scene geometries and various cloud/aerosol configurations. It has a fast twostream algorithm and a more accurate DISORT algorithm to handle the multiple scattering. Given the fact that tens of millions of spectra have to be calculated and DISORT is a very time-consuming approach, we have to adopt a twostream algorithm in the presence of clouds.

[15] To carry out the comparison, we ran CAM2 from September 1996 to September 2003 forced by observed monthly mean sea surface temperature (SST) [Reynolds and Smith, 1994]. The model generated twice-per-day outputs of temperature, humidity, and cloud profiles from July 1 to July 16, 2003, the same period as AIRS data used here. Then these outputs were fed into MODTRAN to generate synthetic spectra. Finally, spectral EOF analysis was applied to these synthetic spectra and the results were compared with what we derived from AIRS data.

\section{Spectral EOF Analysis of AIRS Data Over the Tropical and Subtropical Oceans}

[16] In this section, the results over the tropical and subtropical oceans are presented, with emphasis on the physical interpretations of the three leading principal components, especially the second principal component (PC2).

\subsection{Overview of the Results}

[17] The mean spectrum over the tropical and the subtropical oceans from July 1 to 16 of 2003 is presented in Figure 2. The major spectral features due to absorptions by $\mathrm{H}_{2} \mathrm{O}, \mathrm{O}_{3}, \mathrm{CO}_{2}, \mathrm{CH}_{4}$ and $\mathrm{N}_{2} \mathrm{O}$ are indicated in the figure.
Table 1. Percentage of the Variance Explained by the Leading Three PCs for Different Subsets of AIRS Tropics/Subtropics Data ${ }^{a}$

\begin{tabular}{cccc}
\hline & PC1 & PC2 & PC3 \\
\hline Daytime plus nighttime & $97.0 \%(97.3 \%)$ & $2.2 \%(1.8 \%)$ & $0.5 \%(0.5 \%)$
\end{tabular}
spectra

Daytime spectra only $\quad 97.5 \%(97.5 \%) \quad 1.8 \%(1.75 \%) \quad 0.4 \%(0.4 \%)$ \begin{tabular}{llll} 
Nighttime spectra only $\quad 96.8 \%(96.8 \%)$ & $2.3 \%(2.4 \%)$ & $0.5 \%(0.4 \%)$ \\
\hline
\end{tabular}

${ }^{\mathrm{a}}$ The numbers in parentheses are the results from the spectral EOF analysis to both the continental and the maritime data. Other numbers are from the analysis to the maritime data only.

The principal components, which are to be discussed, are the deviations from this mean spectrum and the spatial patterns show how large the deviations over each grid box are.

[18] Table 1 lists the fraction of variance explained by the three leading principal components when the spectral EOF analysis is applied to different subsets of AIRS data over the tropical/subtropical oceans. It turns out that, as far as the explainable fraction of variance is concerned, there is only a slight difference between the results from different subsets. The PC1 is dominant in all cases. For all subsets listed in Table $1,99.5 \%$ of the variance can be explained by the first three PCs.

[19] The three leading PCs and their spatial maps derived from the tropical/subtropical maritime data are presented in Figures 3 and 4, respectively. The PC1 (Figure 3a) is flat at
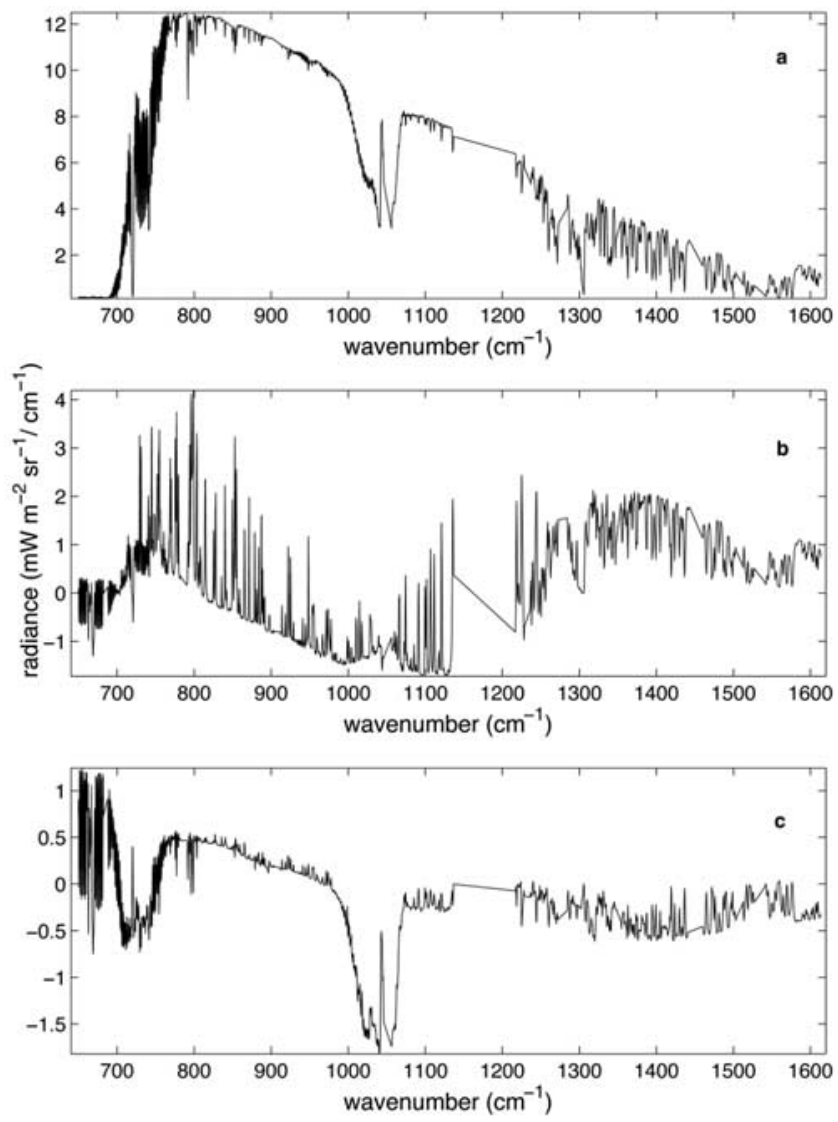

Figure 3. (a) The $\mathrm{PC} 1$ over the tropical/subtropical oceans between $32^{\circ} \mathrm{S}$ and $32^{\circ} \mathrm{N}$ derived from AIRS spectra collected during July $1-16,2003$. (b) The PC2. (c) The PC3. 

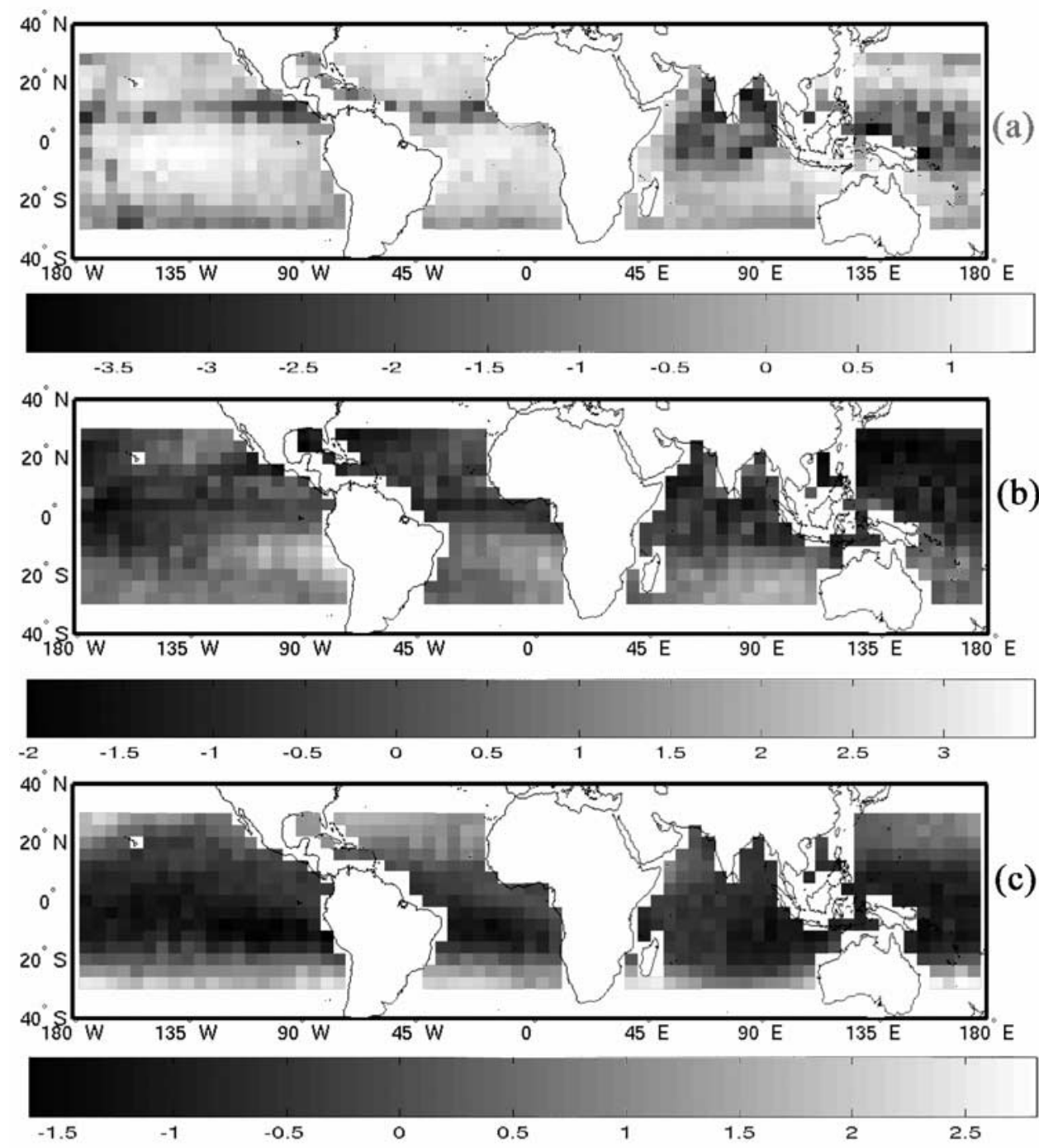

Figure 4. (a) The spatial map of the PC1 shown in Figure 3a. In other words, it is the normalized expansion coefficient of the PC1 computed based on equation (3) in the context. (b) The spatial map of the PC2 shown in Figure 3b. (c) The spatial map of the PC3 shown in Figure 3c. See color version of this figure at back of this issue.

the $\mathrm{CO}_{2} 667 \mathrm{~cm}^{-1}$ band, indicating little contribution from the middle stratosphere to the $\mathrm{PC} 1$. The remaining part of the PC1 resembles the shape of the mean spectrum to a large extent. The minima in the PC1 spatial map (Figure 4a) overlap with the summer ITCZ (Inter Tropical Convergence Zone). Over the Atlantic and the eastern Pacific oceans, the ITCZ is usually narrow in latitude and lies just north of the equator. Over the Indian and the western Pacific oceans, the ITCZ is broad in latitude. All these features of the summer ITCZ [Waliser and Gautier, 1993] can be identified from the PC1 spatial map. Based on the spectral shape of PC1 and its spatial map, it can be concluded that PC1 is due to the contrast of emission temperatures between the cold cloud tops in the presence of optically thick clouds and the warm surface where clouds are absent. When clouds are formed by the deep convection, the clouds are so thick that essentially no radiation emitted from surface can penetrate the cloud. As a result, only emission from the cloud tops or above can be seen from space. PC1 captures the temperature difference between cold cloud tops and the warm surface. This interpretation can be confirmed by examining the correlation coefficient $\left(r_{\text {corr }}\right)$ between the PC1 spatial map and the radiance map of each frequency channel. For some frequency channels in the window region, $r_{\text {corr }}$ can be as high as 0.999 . The good agreement between the PC1 spatial map and the high cloud climatology of July (Figure 5a) derived from ISCCP D2 data [Rossow and Schiffer, 1999] also supports this interpretation.

[20] PC2 shown in Figure $3 \mathrm{~b}$ is more complicated than PC1. It exhibits several spectral features. The $\mathrm{CO}_{2} 667 \mathrm{~cm}^{-1}$ band is not flat, indicating contributions from the stratosphere. The $\mathrm{CO}_{2} 720 \mathrm{~cm}^{-1}$ band peaks downward. The weak water vapor absorption lines in the window region peak upward. The center of the Q-branch of $\mathrm{CH}_{4}$ fundamental band $\left(1306 \mathrm{~cm}^{-1}\right)$ is close to zero. The water vapor $v 2$ band $\left(1595 \mathrm{~cm}^{-1}\right)$ is significantly nonzero, indicating 

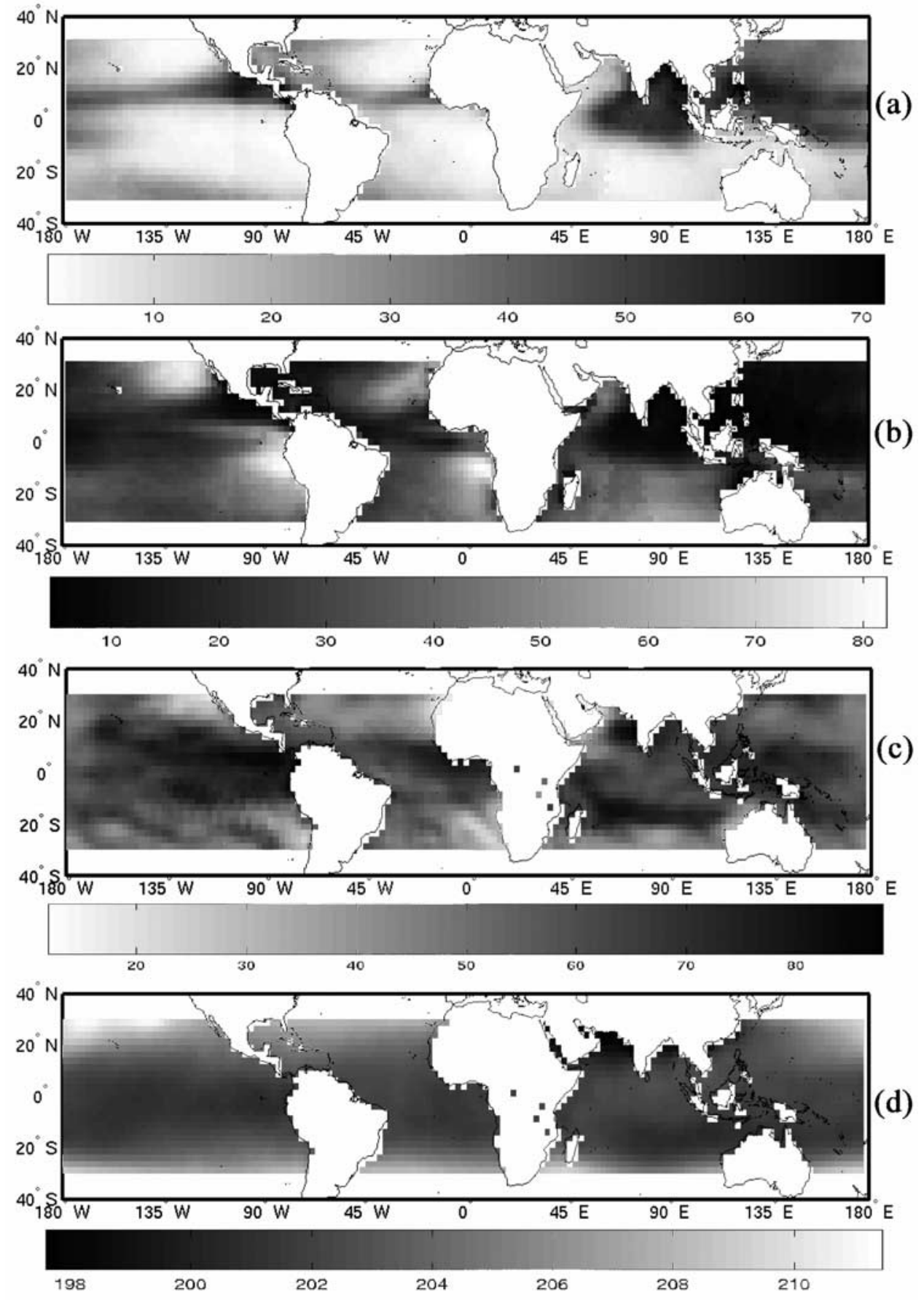

Figure 5. (a) The climatological high cloud amount (in percentage) in July from ISCCP D2 data set. (b) The climatological low cloud amount (in percentage) in July from ISCCP D2 data set. (c) The $850 \mathrm{mb}$ relative humidity (in percentage) averaged over July $1-16,2003$, from NCEP daily reanalysis product. (d) The temperature (in $\mathrm{K}$ ) in the layer of $150 \mathrm{mb}-70 \mathrm{mb}$ averaged over July $1-16$, 2003, also from NCEP. See color version of this figure at back of this issue.

the contributions from upper tropospheric water vapor. The correlation coefficient between the PC2 spatial map and the radiance map of any frequency channel is within \pm 0.6 . The PC2 spatial map (Figure 4b) has local maxima off the coasts of California, Peru, and Namibia as well as over the Canary Islands and the southern ocean west of Australia. These are also regions well known for the high occurrence of low clouds, most notably marine stratus [Klein and Hartmann, 1993]. The PC2 spatial map matches the map of July low cloud climatology (Figure 5b) from ISCCP D2 data very well except over the Arabian Sea and the Atlantic coast off North Africa. When marine stratus is formed, the entrainment at the cloud top tends to dry the layer just above the cloud top [Houze, 1993]. Moreover, 


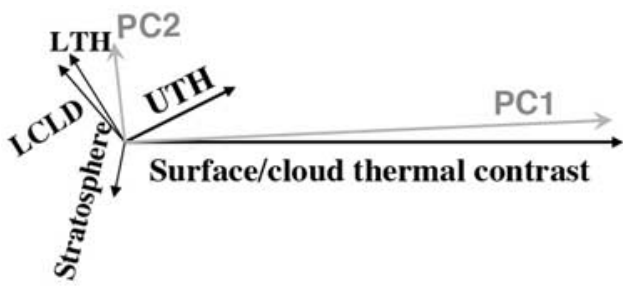

Figure 6. A schematic plot to conceptually demonstrate the results of EOF analysis to a system with correlated factors. LCLD refers to the low cloud. LTH and UTH refer to the lower and upper tropospheric humidity, respectively.

descending branches of large-scale circulation could decrease LTH by subsidence drying and help maintaining temperature inversion in the lower troposphere, a condition essential to the formation and persistence of low cloud [Houze, 1993]. Therefore, the low cloudiness usually negatively correlated with the lower tropospheric relative humidity. As a result, the minima in the map of $850 \mathrm{mb}$ relative humidity (Figure 5c) derived from NCEP daily reanalysis data [Kalnay et al., 1996] from July 1-16, 2003 also consistently correlated to the maxima in the PC2 spatial map except the Arabian Sea and the Atlantic coast off the North Africa. These spatial features suggest that PC2 could be mostly due to the low cloud and the lower tropospheric humidity (LTH) variations. PC2 also captures other variations because of the forced orthogonality to PC1. Further interpretation of the PC2 will be given in the next subsection.

[21] The third principal component, PC3, accounts only for $\sim 0.4 \%$ of the total variance. Nevertheless its spectral shape and spatial pattern are still meaningful. The spectral features at the $\mathrm{CO}_{2} 667 \mathrm{~cm}^{-1}$ and $720 \mathrm{~cm}^{-1}$ bands and the $\mathrm{O}_{3} 1042 \mathrm{~cm}^{-1}$ band are significantly nonzero. For the other parts, it is close to zero. These imply that PC 3 is mainly due to the temperature variations in the stratosphere and the upper troposphere, to which the aforementioned three bands are sensitive. Ozone in the lower stratosphere can also contribute to the PC3 significantly given the large meridional gradient of lower-stratospheric ozone over this region. The PC3 spatial map (Figure 4c) is zonally uniform. The negative (positive) values in the PC3 spatial map indicate colder (warm) brightness temperature at $\mathrm{CO}_{2} 667 \mathrm{~cm}^{-1}$ band than the mean spectrum. This is consistent with the fact that the tropical lower stratosphere is colder than the subtropical counterpart. The maximum correlation coefficient between the PC3 spatial map and the radiance map of a given AIRS frequency channel is 0.9. The corresponding frequency channel is $651.3 \mathrm{~cm}^{-1}$ with the contribution function peaking at $117 \mathrm{mb}$, further confirming the lower stratosphere and the upper troposphere as the major contributors to PC3. The map of the NCEP upper tropospheric and lower stratospheric temperature averaged over the same period (Figure 5d) generally agrees with the PC3 spatial map. This also supports the interpretation of PC3.

[22] If the continental data are included in the analysis, the spectral shapes of the $\mathrm{PC} 1$ and the $\mathrm{PC} 2$ are basically the same. However, the amplitude of the PC1 is larger because of the larger surface/cloud top thermal contrast when continental deserts are included. The slopes at the window regions of the $\mathrm{PC} 2$ and the $\mathrm{PC} 3$ are different. The possible causes for this difference in slope are (1) the spectrally dependent surface emissivity in the window region can vary significantly for different types of land surface [Wilber et al., 1999]; (2) the subtropical continental warm clouds usually have smaller effective radii than the subtropical maritime warm clouds due to the maritime-continental contrast of the number of $\mathrm{CCN}$ (cloud condensation nuclei) [Han et al., 1994], and the different cloud effective radii can affect the slope in the window region even when the cloud optical depths are the same [King et al., 1992; Prabhakara et al., 1988]. The spatial maps of the three leading PCs derived from all data over the tropics/subtropics are consistent with the maps shown in Figure 4.

[23] Examining AIRS data over the tropical and the subtropical oceans from January 01 to January 16 of 2003 with the spatial-spectral EOF technique yields similar results. The PC1 spatial map shows minima over the wintertime ITCZ, the PC2 spatial map is consistent with the January low cloud climatology, and the PC3 spatial map shows patterns resembling the upper tropospheric and the lower stratospheric temperature variations.

\subsection{Further Interpretation of $\mathbf{P C 2}$}

[24] The PC2 spatial map shows features consistent with the map of low cloud amount, but its spectral shape shows contributions from the stratosphere (the nonzero $\mathrm{CO}_{2}$ $667 \mathrm{~cm}^{-1}$ band) and the upper tropospheric water vapor (the nonzero water vapor $1596 \mathrm{~cm}^{-1}$ band) as well. This can be understood in terms of the forced orthogonality between each principal component and its predecessors. Figure 6 is a schematic diagram showing a system with several factors contributing to the variability of the system. These factors might be neither independent of ("orthogonal"), nor totally dependent on ("parallel"), each other. For example, at the ascending branch of the Hadley Circulation or the Walker Circulation, high clouds would form and upper troposphere humidity (UTH) would be enriched by convection; at the descending branch, the upper troposphere would be dehydrated and a temperature inversion layer would form in the lower troposphere that promotes the formation of marine stratus [Houze, 1993]. Therefore, the variation in UTH is correlated with the changes of both high cloud and low cloud. Meanwhile, if one of these factors contributes to the variance much more than any other factors, PC1 from the EOF analysis would be similar to the imprint of this dominant factor. But PC1 would not be identical to the imprint of this dominant factor because, as long as these factors are not "orthogonal" to each other, the PC1 always tries to capture projections from other factors so that the fraction of variance it can explain is maximized. Therefore, PC1 would be slightly different from the imprint of the dominant factor. Given the fact that $\mathrm{PC} 2$ is forced to be orthogonal to $\mathrm{PC} 1$, these factors would have projections onto PC2 too. The one having the largest projection onto PC2 (the factor "nearest" to PC2) would be seen from the PC2 spatial map more easily than any other factors. In this case, LTH and the low cloud, two factors which are closely related to each other, should be the factors "nearest" to the PC2, as sketched in Figure 6. Therefore, the PC2 spatial map has good agreement with the spatial map of LTH and the low cloud. Meanwhile, the PC2 also has projections 

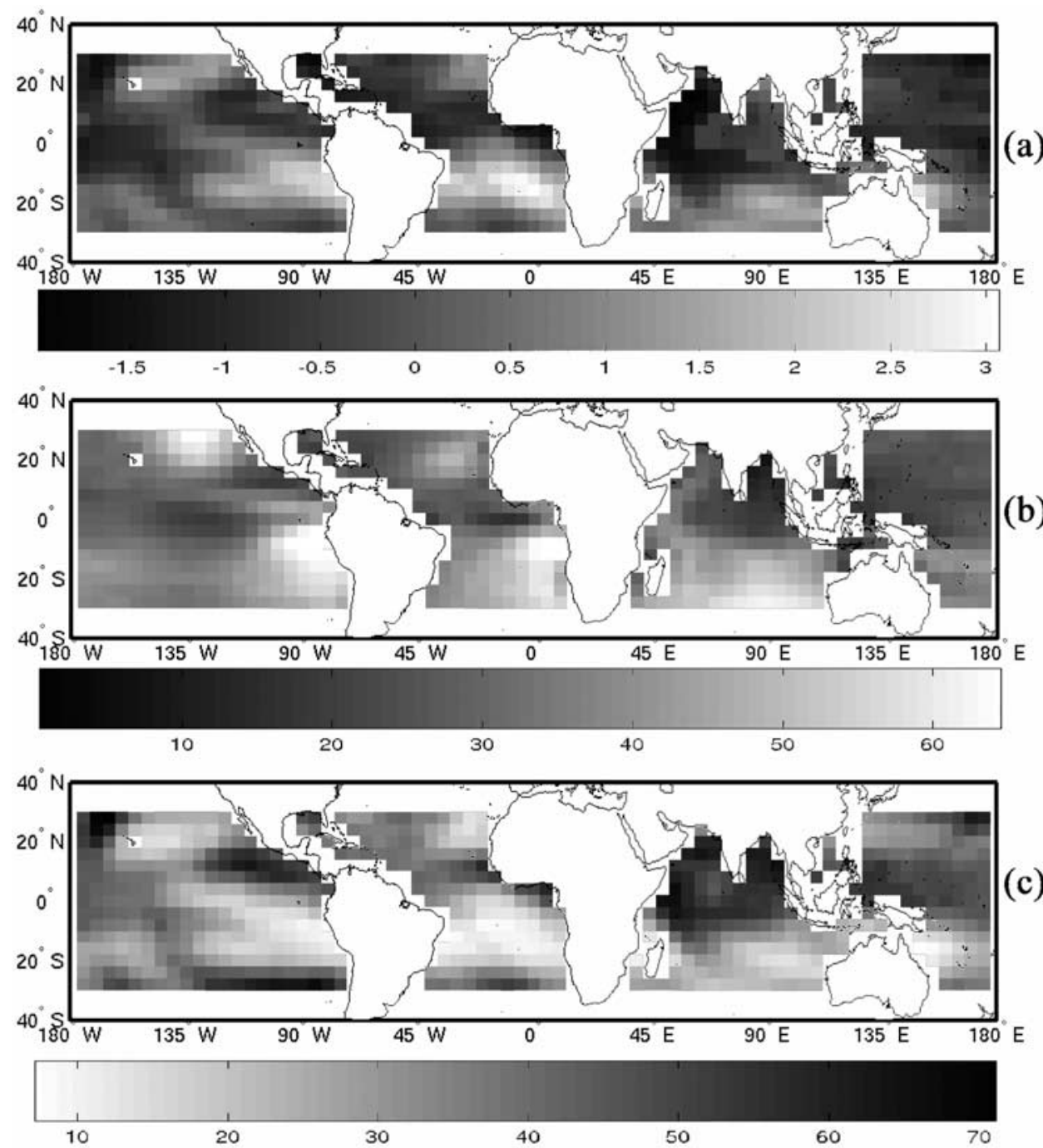

Figure 7. (a) The PC2 spatial map of the simulated NCEP + ISCCP cloudy case. Refer to the context for the definitions of the ISCCP cloudy case. (b) The ISCCP climatological low cloud amount (in percentage) used in the simulation. It is identical to Figure $5 \mathrm{~b}$ except that it has been smoothed to $4^{\circ}$ latitude by $5^{\circ}$ longitude resolution. (c) The NCEP relative humidity (in percentage) of 300-500 mb layer averaged over July $1-16,2003$, smoothed to $4^{\circ}$ latitude by $5^{\circ}$ longitude resolution. See color version of this figure at back of this issue.

from the upper tropospheric humidity and the stratosphere, which are shown in its spectral signature.

[25] To further understand the effect of cloud on the PC2, we carry out two simple simulations using NCEP daily reanalysis data from July 01 to July 16, 2003 and ISCCP July climatology of cloud distribution and cloud optical depth. The first simulation (hereafter, clear-sky case) computes the spectra based on NCEP 16-day average of temperature and humidity profiles over each $4^{\circ}$ by $5^{\circ}$ grid box with no cloud information included. The second simulation (hereafter, NCEP + ISCCP cloudy case) computes the spectra based on both NCEP data and ISCCP July climatology of cloud amount, cloud height, as well as cloud optical depth over each grid box. Both simulations are done using MODTRAN. (The highest spectral resolution (FWHM) that MODTRAN can correctly generate is $2 \mathrm{~cm}^{-1}$. For AIRS, its resolution varies with frequencies and is about $0.5 \sim 1.0 \mathrm{~cm}^{-1}$ in the spectral range that we look at.
This difference in spectral resolution should have little impact on the EOF results. More detailed discussion is given in section 5.) We apply spectral EOF analysis to these two sets of synthetic spectra in the same way as we apply it to AIRS data. For the clear-sky case, the PC1 and the PC2 can explain $88 \%$ and $10 \%$ of the total variance, respectively. This is because the PC1 of the clear-sky case is mainly due to the emission surface temperature contrast between different regions and this contrast is significantly smaller than the contrast between the surface and cold cloud tops. The PC2 spatial map of the clear-sky case has a correlation coefficient of 0.996 with the radiance map at $1244 \mathrm{~cm}^{-1}$, a channel which is sensitive to water vapor and has a weighting function peaking at $\sim 550 \mathrm{mb}$. Given that the nadir-view weighting function usually has a broad width in the thermal IR region, [Goody and Yung, 1989], this good correlation means that PC2 is essentially due to the variation of the 

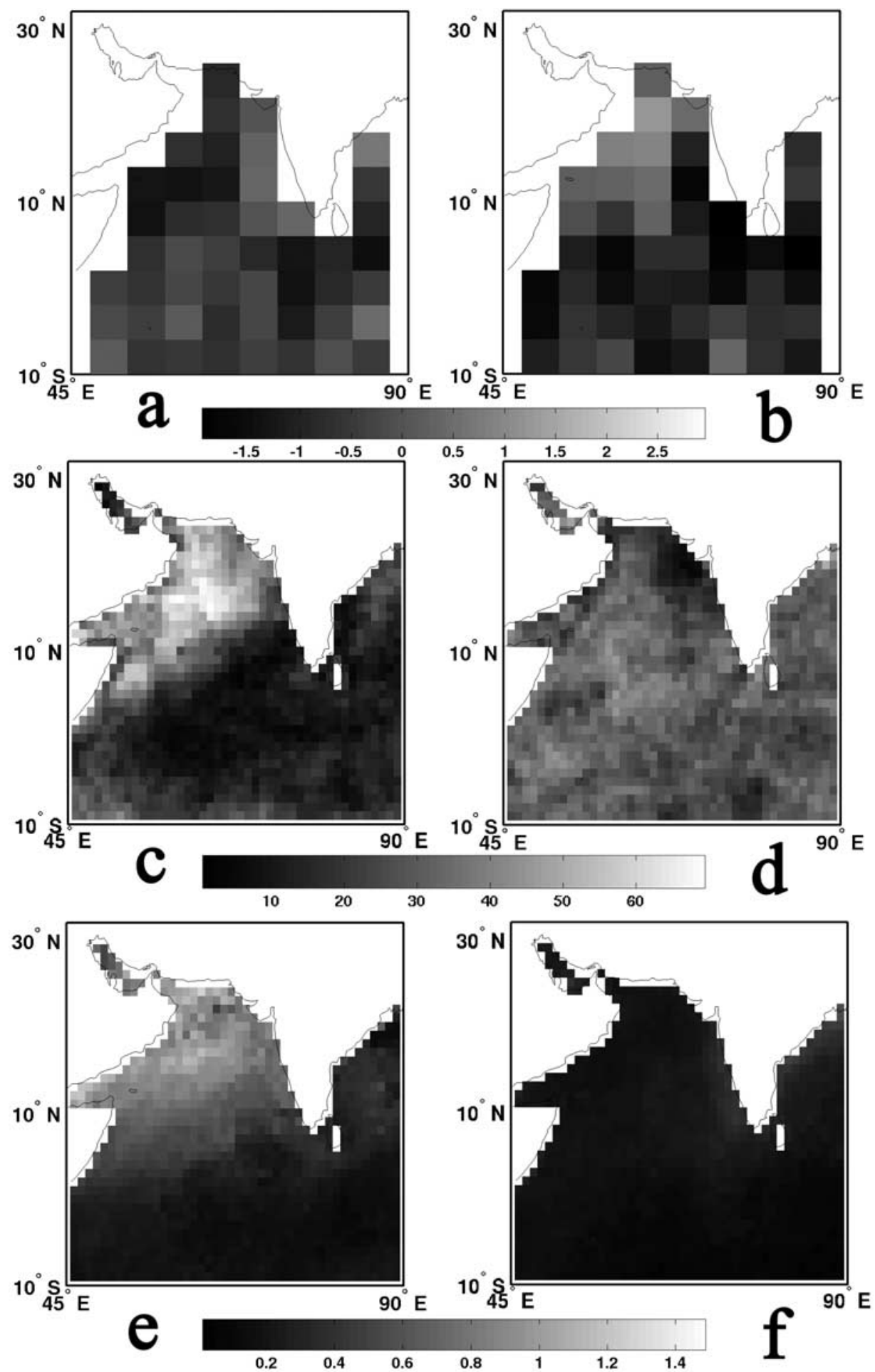

Figure 8. (a) The PC2 over the Arabian Sea derived from AIRS data over July 1-16, 2003. (b) Same as Figure 8a for January 1-16, 2003. (c) The monthly mean low cloud amount of July 2003 derived from MODIS observation. (d) Same as Figure 8c for January 2003. (e) The monthly mean aerosol optical depth of July 2003 derived from MODIS observation. (f) Same as Figure 8e for January 2003. See color version of this figure at back of this issue. 
Table 2. Percentage of Variance Explained by Three Leading PCs Over NHMO and SHMO

\begin{tabular}{lccc}
\hline & PC1 & PC2 & PC3 \\
\hline $32^{\circ} \mathrm{N}-60^{\circ} \mathrm{N}$ & $97.7 \%$ & $1.7 \%$ & $0.5 \%$ \\
$32^{\circ} \mathrm{S}-60^{\circ} \mathrm{S}$ & $97.3 \%$ & $1.8 \%$ & $0.6 \%$ \\
\hline
\end{tabular}

water vapor density over a broad layer centered at $550 \mathrm{mb}$, or approximately the variation of the column water vapor abundance. Therefore, the first two PCs for the clear-sky case are mainly due to the variation of surface temperature and the variation of column water abundance, respectively.

[26] For the NCEP + ISCCP cloudy case, the PC2 spatial map is not highly correlated with the radiance map of any channel: all correlation coefficients are within \pm 0.77 , similar to the situation of the AIRS PC2. Moreover, the spatial map as shown in Figure $7 \mathrm{a}$ is in a good agreement with the low cloud amount map used in this simulation (Figure $7 \mathrm{~b}$ ). Therefore, when cloud is included, the variation of cloud top (mostly high cloud top) is "aliased" to the PC1 and the variation of low cloud is "aliased" to the PC2.

[27] Figure 7c shows the NCEP upper tropospheric relative humidity (UTH) map averaged over July 1-16, 2003. Compared to the LTH, e.g. $850 \mathrm{mb}$ relative humidity shown in Figure 5c, UTH is distributed more uniformly along latitude band: high UTH over the ITCZ and low UTH over broad subsidence regions. The AIRS PC2 spatial map (Figure 4b) features with localized maxima, which is more consistent with maps of LTH and low cloud rather than map of UTH. The same conclusion also holds for the PC2 spatial map derived from ISCCP + NCEP simulation. Given the fact that ISCCP does not provide detailed cloud microphysical properties or vertical resolution, this ISCCP + NCEP simulation is a rather crude simulation. Yet it supports our interpretation of the $\mathrm{PC} 2$ and the fingerprints of $\mathrm{UTH}$ for both the PC1 and the PC2 due to the forced orthogonality.

[28] Traditionally visible reflectance is used to observe low clouds because of its high albedo in the visible range. The relatively small thermal contrast between the surface and low cloud tops makes direct observation of low clouds from IR window channels of meteorological satellites difficult. Here we show that, using spatial-spectral EOF to decompose the thermal IR spectra, the variation of low clouds and associated LTH in the tropical and subtropical oceans can be clearly seen in the PC2 and its spatial map.

\subsection{Fingerprint of Dust Aerosol in the PC2}

[29] From the discussion in previous subsections, it can be seen that the local maxima in the AIRS PC2 spatial map occur in the regions which are constantly covered by low clouds with two exceptions: the Arabian Sea and the Atlantic coast off North Africa. From the ISCCP climatology of low cloud amount (Figure 5b), these two regions are frequently covered by low clouds. However, in the AIRS PC2 spatial map, there is a local minimum rather than a local maximum over the Arabian Sea and the local maximum over the Atlantic coast off North Africa is much weaker than other local maxima over the regions constantly covered by low cloud. These two exceptions are to be discussed in this subsection.
[30] In order to understand these two exceptions, it would be useful to compare the AIRS PC2 spatial map during July $1-16,2003$ to the counterpart during January 1-16, 2003. In July, the atmosphere is usually heavily loaded with dust aerosols in these two regions with the visible optical depth around $0.4-0.8$, a phenomenon seen by several satellite instruments such as AVHRR [Husar et al., 1997], MODIS [King et al., 2003], and TOMS [Herman et al., 1997; Prospero et al., 2002], as well as surface observations [Ackerman and Cox, 1989; Middleton, 1986]. In January, little dust aerosol is present over these two regions. The July AIRS PC2 spatial map and the monthly averaged low cloud amount and aerosol optical depth derived from MODIS observations over the Arabian Sea in July 2003 are shown in Figures 8a, 8c, and 8e, respectively. For comparison, the similar results for January 2003 are shown in Figures 8b, $8 \mathrm{~d}$, and 8f, respectively. For both January and July 2003, low cloud amount was prominent over this region. In January 2003, aerosol optical depth was about or less than 0.1 and there was a local maximum over the Arabian Sea in AIRS PC2 spatial map, consistent with what we have argued in sections 3.1 and 3.2. In July 2003, aerosol optical depth was about 1 and there was a local minimum over this region in AIRS PC2 spatial map. Dust (both carbonate and mineral) has absorption bands in the thermal IR. So it is possible that the heavy dust aerosol loading leaves its
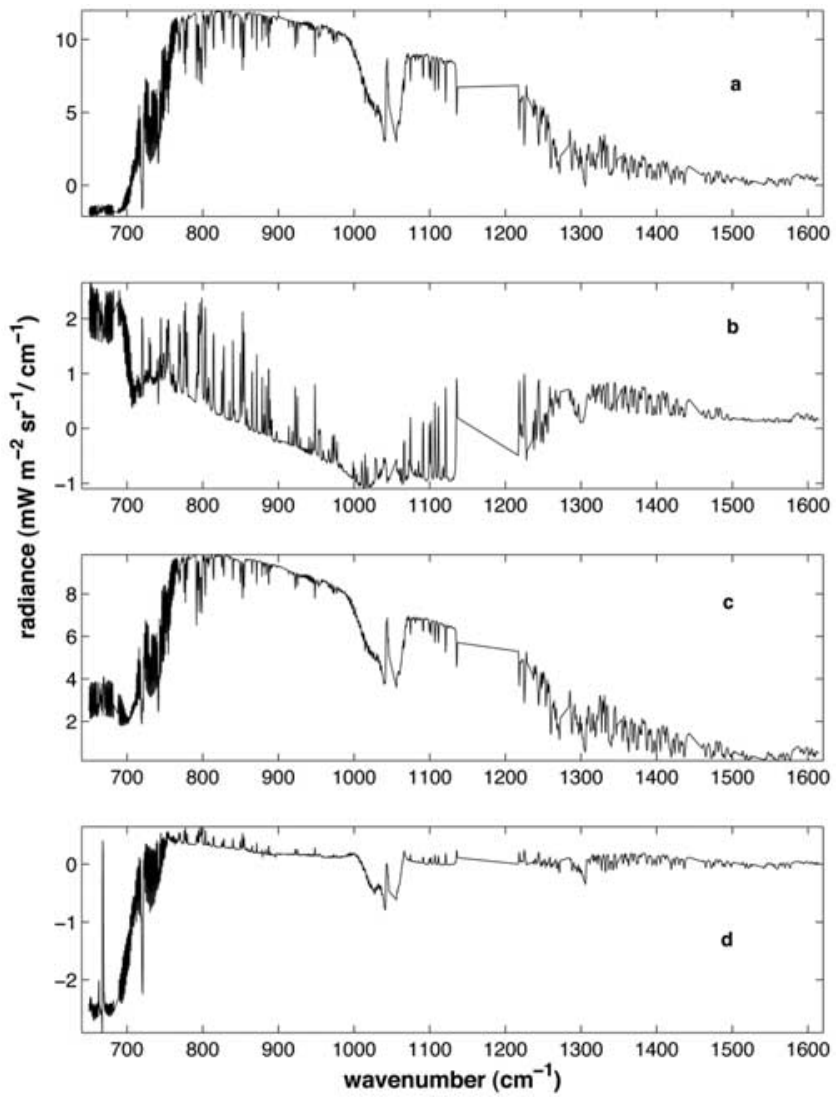

Figure 9. The $\mathrm{PC} 1 \mathrm{~s}$ and $\mathrm{PC} 2 \mathrm{~s}$ over the $\mathrm{NHMO}$ and the SHMO. (a) The PC1 over the NHMO. (b) The PC2 over the NHMO. (c) Same as Figure 9a for the SHMO. (d) Same as Figure $9 b$ for the SHMO. 

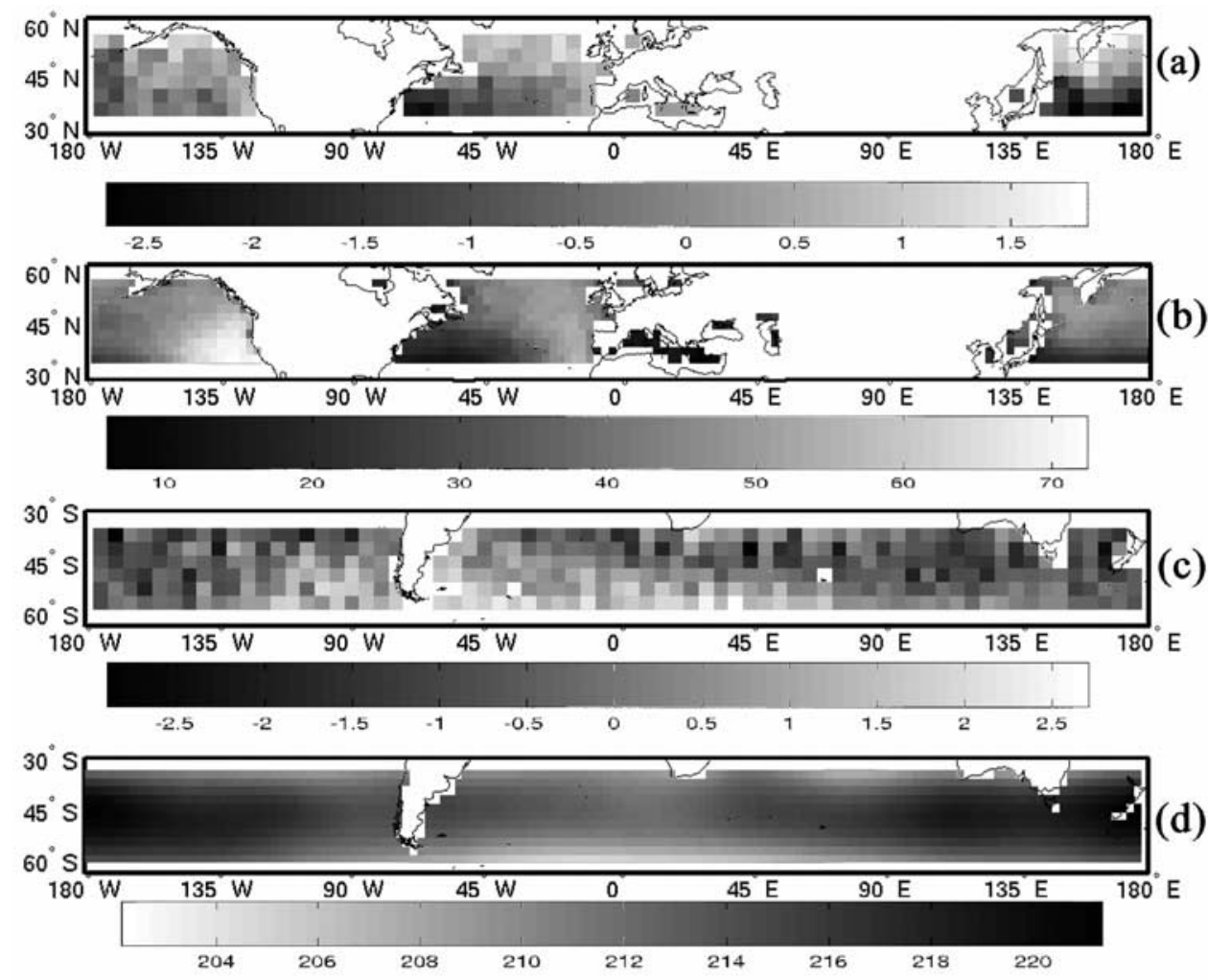

Figure 10. (a) The PC2 spatial map over the NHMO. (b) The ISCCP climatological low cloud amount of July over the same regions as Figure 10a. (c) The PC2 spatial map over SHMO. (d) The NCEP 16-day (July $1-16,2003$ ) average of $100 \mathrm{mb}$ temperature over the same regions as Figure 10c. See color version of this figure at back of this issue.

fingerprint in the AIRS spatial-spectral EOF analysis. This, in turn, reverses a local maximum due to low cloud to a local minimum due to dust. Two additional observational facts support this argument:

[31] 1. Several studies [Li and Ramanathan, 2002; Prospero et al., 2002; Tindale and Pease, 1999] suggest that dust is transported in the middle troposphere (around $700 \mathrm{mb}$ ) to the Arabian Sea. Low clouds usually top around $850 \mathrm{mb}$. Therefore dust aerosol is most likely above the low clouds and can be seen first from a nadir-view satellite IR sounder like AIRS. The more optically thick the dust aerosol is, the less AIRS can see through the dust aerosol layer. Dust blowing off the Atlantic coast of North Africa is also transported around the similar altitude [Karyampudi et al., 1999].

[32] 2. A previous observational study [Ackerman, 1997] shows that, for the thermal IR radiances collected in the presence of a dust storm over the Arabian Sea, the brightness temperature difference between $8 \mu \mathrm{m}$ and $11 \mu \mathrm{m}$ (hereafter, $\Delta \mathrm{BT}_{8-11}$ ) tends to be negative because most common elemental components of dust have maximal absorption around $8 \mu \mathrm{m}$ and minimal absorptions around $11 \mu \mathrm{m}$. In contrast, existence of low clouds (liquid water clouds) tends to make $\Delta \mathrm{BT}_{8-11}$ positive because water has a larger absorption coefficient at $11 \mu \mathrm{m}$ than at $8 \mu \mathrm{m}$ [Ackerman et al., 1990]. In other words, the dust aerosol and the low cloud have opposite effects on the slope of the window region. This explains why the existence of dust aerosol reverses a local maximum to a local minimum.
[33] These facts physically explain why the heavy dust loading over these two regions in July can erase the imprints of low clouds in PC2 and even reverse it from a local maximum to a local minimum.

\section{Midlatitude Oceans}

[34] Table 2 summarizes the fraction of variance explained by the three leading PCs over the northern hemisphere midlatitude oceans $\left(32^{\circ} \mathrm{N}-60^{\circ} \mathrm{N}\right)$ and the southern hemisphere midlatitude oceans $\left(32^{\circ} \mathrm{S}-60^{\circ} \mathrm{S}\right.$ ) (for brevity, hereafter NHMO and SHMO, respectively). Similar to the case of the tropical/subtropical oceans, the PC1 is absolutely dominant here and three leading PCs together can explain more than $99.5 \%$ of the variance.

[35] The spectral shapes of the PC1s over the NHMO and the SHMO (shown in Figures 9a and 9c) are similar to those of the PC1 over the tropical/subtropical oceans except that both midlatitude $\mathrm{PC} 1 \mathrm{~s}$ capture a small contribution from the stratosphere shown in the $\mathrm{CO}_{2} 667 \mathrm{~cm}^{-1}$ band. $\mathrm{PC} 1 \mathrm{~s}$ here are still mainly due to the contrast of emission temperatures, including the poleward variation in surface temperature and the temperature contrast between the surface and cloud tops.

[36] The PC2 over the NHMO (Figure 9b) shows spectral features at the $\mathrm{CO}_{2} 667 \mathrm{~cm}^{-1}$ band as well as weak water vapor absorption lines in the window region. The spatial map of PC2 over the NHMO (Figure 10a) has maxima over the North Pacific, the North Atlantic and near the west 

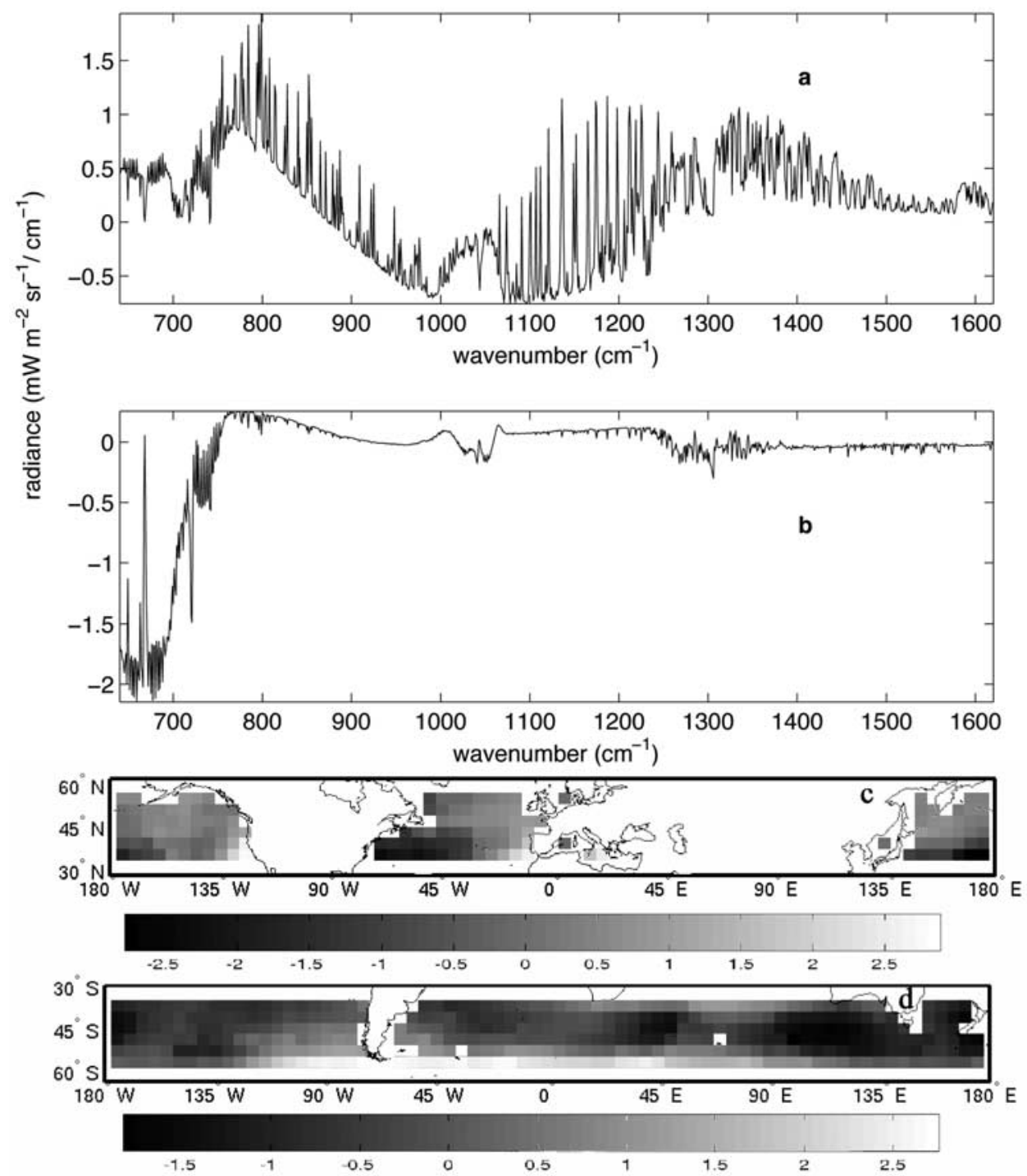

Figure 11. (a) The PC2 over the NHMO derived from the NCEP + ISCCP case. (b) The PC2 over the SHMO derived from the NCEP + ISCCP case. (c) The spatial map associated with the PC2 in Figure 11a. (d) The spatial map associated with the PC2 in Figure 11b.

coast of North America, consistent with ISCCP July low cloud climatology (Figure 10b). The interpretation of this PC2 is similar to the PC2 over the tropical/subtropical oceans: it is mainly due to the variation of LTH and low clouds but captures the variation from the stratospheric temperature as well due to the forced orthogonality by EOF analysis.

[37] The PC2 over the SHMO (Figure 9d) has two sharp spikes at the centers of the $\mathrm{CO}_{2} 667 \mathrm{~cm}^{-1}$ and $720 \mathrm{~cm}^{-1}$ bands. Outside these two $\mathrm{CO}_{2}$ bands and the $\mathrm{O}_{3}$ band, the PC2 is rather flat and close to zero. This clearly indicates that the PC2 is due to the temperature changes in the stratosphere and the upper troposphere. The spatial map of PC2 shown in Figure 10c has maxima (corresponding to a cold stratosphere) at the margin of the polar vortex and minima (corresponding to a warm stratosphere) over the midlatitude southern ocean, consistent with the $100 \mathrm{mb}$ temperature map (Figure 10d) derived from NCEP daily reanalysis product over the same period.
[38] Applying spectral EOF analysis to the synthetic spectra over the NHMO and the SHMO based on the NCEP reanalysis daily product over the same period and ISCCP climatology in July (hereafter, NCEP + ISCCP case), we can obtain similar results. Figure 11 shows the PC2s and their spatial maps from such analysis. It can be seen that, for both the spectral features and their spatial maps, the PC2s from this NCEP + ISCCP case agree with the AIRS PC2s reasonably well except for the $\mathrm{CO}_{2} 667 \mathrm{~cm}^{-1}$ band of the PC2 over the NHMO. The spatial map of the PC2 over the NHMO (Figure 11c) shows maxima over those areas frequently covered by low clouds, consistent with the low cloud climatology used in this simulation (Figure 10b). The spatial map of the PC2 over the SHMO (Figure 11d) is consistent with the spatial distribution of NCEP upper tropospheric and lower stratospheric temperature variations (Figure 10d).

[39] From the above paragraph, the PC2 over the SHMO has a different spectral character and a different explanation 


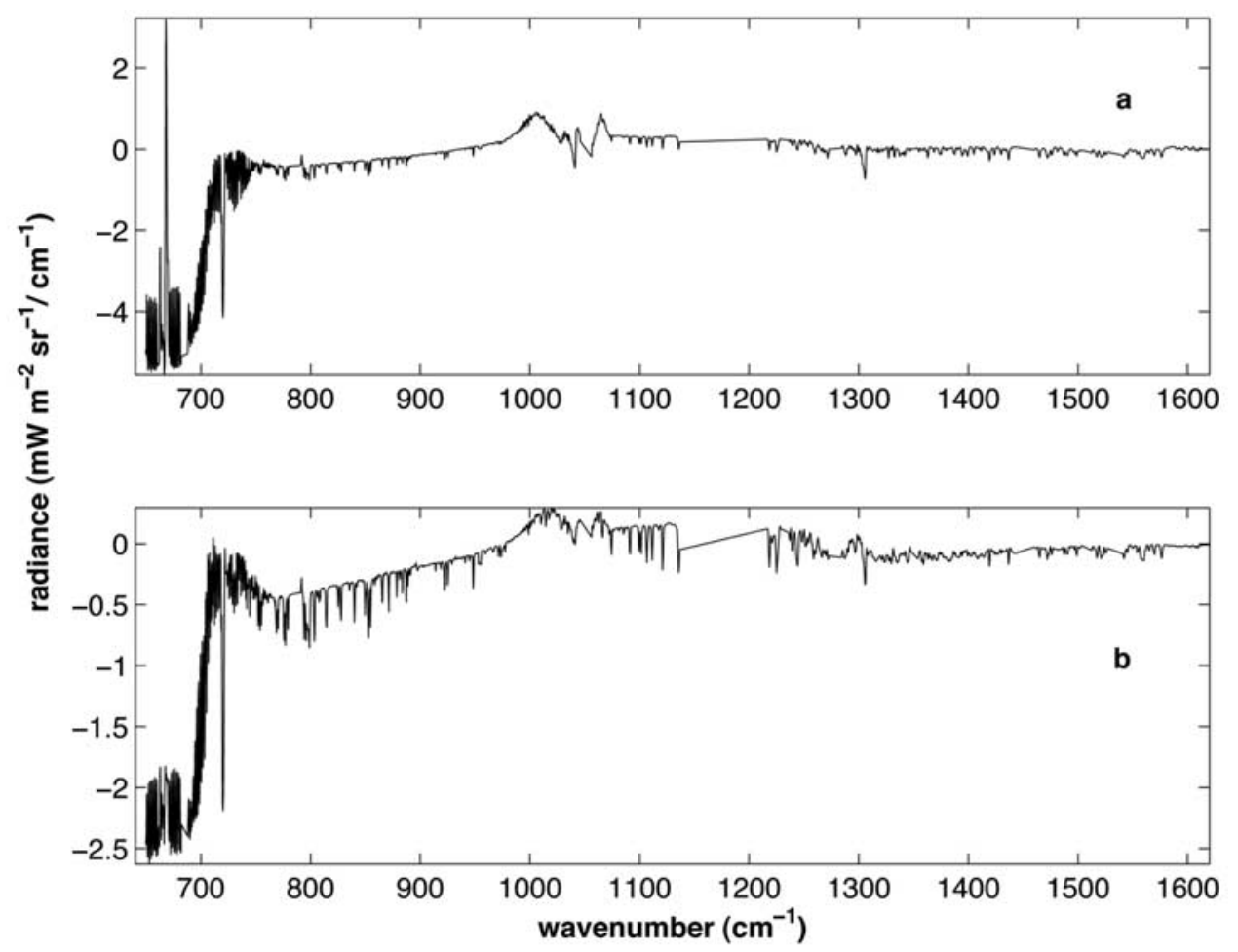

Figure 12. The PC2s from the spatial-spectral EOF analysis of AIRS data over January 1-16, 2003. (a) The PC2 over the NHMO. (b) The PC2 over the SHMO.

from that over the NHMO. This is partially due to the summer-winter contrast between the NHMO and the SHMO. To further understand these differences, it would be instructive to examine the PC2s from January AIRS data. The PC2s over the NHMO and the SHMO derived from AIRS data over January $01-16,2003$ are shown in Figure 12. The PC2 over the NHMO in January (Figure 12a) resembles the PC2 over the SHMO in July, both having two sharp spikes at the centers of two $\mathrm{CO}_{2}$ bands and relatively flat window region and water vapor band. However, the PC2 over the SHMO in January (Figure 12b) is not similar to the PC2 over the NHMO in July: it mainly shows the stratospheric contributions although it captures the variations in the weak water vapor absorption lines in the window region.

[40] The similarity between the wintertime $\mathrm{PC} 2 \mathrm{~s}$ over the NHMO and the SHMO is due to the strong disturbance of the stratosphere in winter by the vertical propagation of the planetary waves originated in the troposphere [Holton, 1983]. As a result, the spatial variation of the stratospheric temperature is so large that its contribution to the variance of spectra is second only to the emission temperature contrast. In the summertime, the stratosphere is relatively undisturbed due to the existence of the critical surface (zero zonal wind) in the lower stratosphere [Charney and Drazin, 1961; Holton, 1983]. Meanwhile, owing to the greater land-sea contrast in the northern hemisphere than in the southern hemisphere, the lower tropospheric humidity and the low clouds at the summertime NHMO exhibit larger spatial variations than those at the summertime SHMO. As a result, the PC2 over the summertime NHMO is "biased" to the variations of the LTH and the low cloud and the PC2 over the summertime SHMO is still mostly due to the variation of the stratospheric temperature.

\section{Results From CAM2 Simulation}

[41] In this section we present a spatial-spectral EOF analysis of synthetic spectra based on CAM2 simulations. An eight-year CAM2 T42 run (corresponding to a spatial resolution of $2.8^{\circ}$ latitude by $2.8^{\circ}$ latitude) forced by observed monthly SST from 1996 to 2003 is carried out. The twice-per-day output from July $01-16$ of 2003 is fed into MODTRAN to generate synthetic spectra and these spectra are resampled to AIRS spectral sampling points, then spatial-spectral EOF analysis is applied to these synthetic spectra. The purpose of this analysis is not to perform a strict and rigorous comparison between GCM and AIRS observations. Instead, this is a case study to demonstrate what we can obtain from synthetic radiance and the feasibility of model-to-satellite comparison using spectrally resolved radiance.

[42] Limited by the capability of MODTRAN, the synthetic spectra have different spectral resolution $\left(1 \mathrm{~cm}^{-1}\right)$ from AIRS spectra $(\lambda \Delta \lambda=1200$, corresponding to $0.5-$ $1.3 \mathrm{~cm}^{-1}$ over the interested spectral range). The impact of this difference in spectral resolution on EOF analysis is investigated in Appendix A. It turns out that it has a very minor impact on results of EOF analysis, especially the spatial map.

\subsection{Tropical/Subtropical Oceans}

[43] The three leading PCs (hereafter, CAM2 PCs) in this climate zone and their spatial maps are shown in Figure 13. 

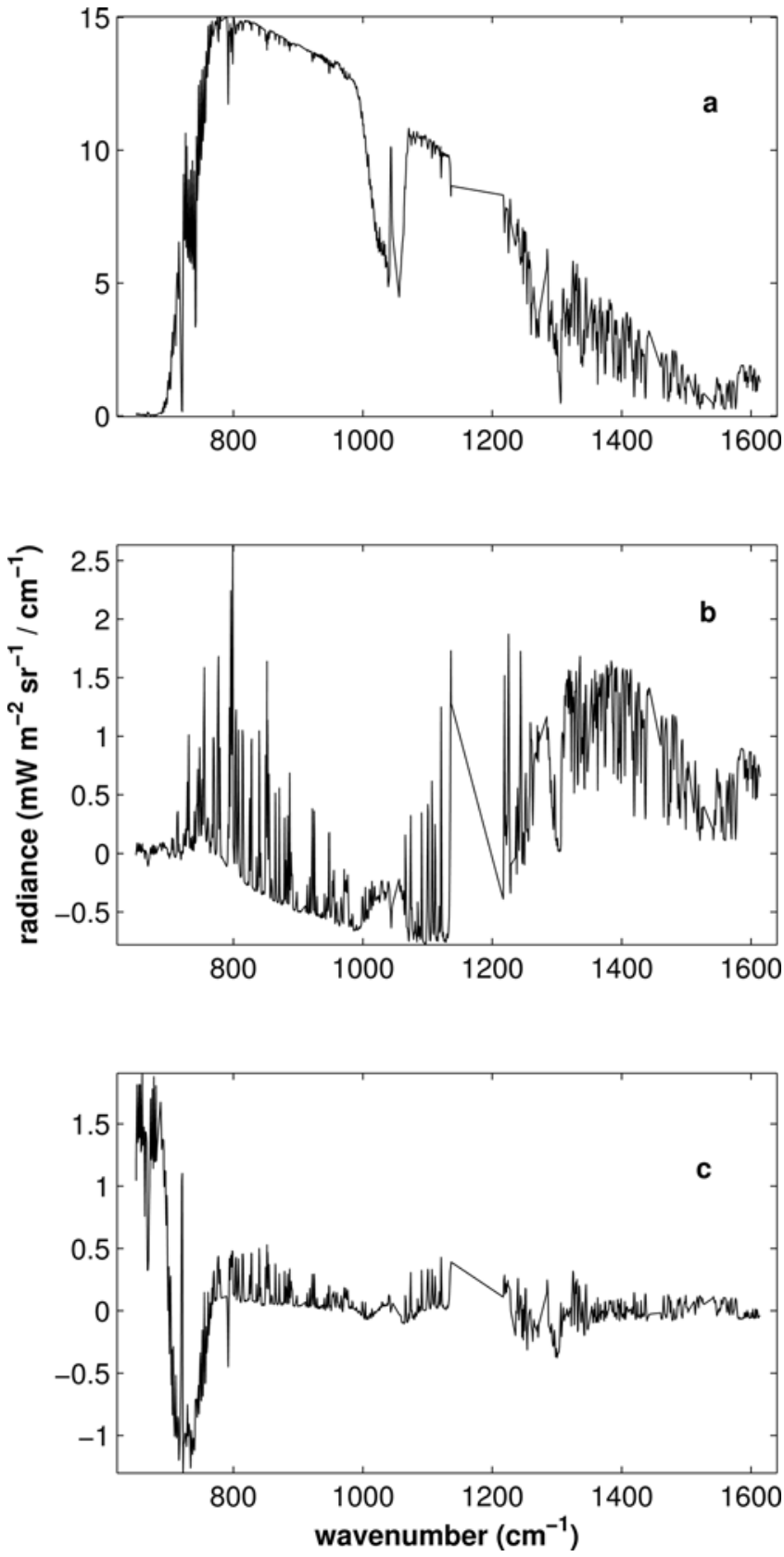

Figure 13. (a) The $\mathrm{PC} 1$ at the tropical/subtropical oceans based on the CAM2 simulation. (b) The PC2. (c) The PC3. (d) The PC1 spatial map. (e) The PC2 spatial map. (f) The PC3 spatial map.

The fraction of variance explained by each $\mathrm{PC}$ is listed in Table 3. The spectral features of these PCs agree well with those of AIRS PCs shown in Figure 3 except that the spectral features at the $\mathrm{O}_{3}$ band are missing in the CAM2 PC3. This missing spectral feature at the $\mathrm{O}_{3}$ band is due to the fact that a fixed typical tropical ozone profile has been used in all MODTRAN calculations but, in reality, ozone profiles have very large meridional gradients in the tropics and subtropics. The spatial maps also agree reasonably well with those derived from AIRS spectra (Figure 4). The major discrepancies are as follows:
[44] 1. Position of the western Pacific ITCZ: between $135^{\circ} \mathrm{E}$ to $180^{\circ} \mathrm{E}$, the $\mathrm{CAM} 2 \mathrm{PC} 1$ spatial map indicates little high cloud cover around the equator and substantial high cloud cover over the northern hemisphere subtropics. In the AIRS PC1 spatial map, the situation is just the opposite.

[45] 2. Double ITCZ over the central Pacific: the CAM2 PC1 spatial map shows a more prominent "double ITCZ" in the region than the AIRS PC1 spatial map.

[46] 3. Dust aerosol over the Arabian Sea and the Atlantic coast off North Africa: as discussed in section 3.3, the local minimum over the Arabian Sea and the weak local maximum off the Atlantic Coast of North Africa in AIRS PC2 spatial map are results of heavy loading of dust aerosol. In CAM2 simulation, only background aerosol has been used. Therefore, low clouds are not shadowed by dust aerosol and there are local maxima over both regions in CAM2 PC2 spatial map.

[47] Apparently discrepancies 1 and 2 are related to how well the ITCZ can be simulated by an atmospheric GCM. The latitudinal preference of the ITCZ could be regulated by many physical mechanisms. The spatial distributions of SST and low-level convergences are thought to play major roles in regulating the location of the ITCZ [Bjerknes et al., 1969; Holton et al., 1971] and these ideas are supported by many numerical studies [Goswami et al., 1984; Manabe et al., 1974; Waliser and Somerville, 1994]. In term of the simulation of the ITCZ by GCMs, several studies show the high sensitivity of the latitudinal preference of the ITCZ to the convection parameterization scheme used in GCMs [Chao, 2000; Chao and Chen, 2001; Hess et al., 1993]. Given the complex mechanism for regulating the location of the ITCZ and the important role of air-sea interaction and subgrid convective activities in such regulation, it is not surprising that an AGCM alone cannot satisfactorily simulate the latitudinal preference of the ITCZ over a short period of 16 days. As for discrepancy 3, it shows the necessity of including time-dependent dust aerosol profiles in GCM simulation. Dust aerosol can absorb both the shortwave and longwave radiation. As a result, when there is heavy dust aerosol loading in the atmosphere, it will have a significant impact on the radiative heating rate [Carlson and Benjamin, 1980] and consequently on the circulation pattern [Mohalfi et al., 1998].

\subsection{Midlatitude Oceans}

[48] The fractions of variances explained by the three leading CAM2 PCs at NHMO and SHMO over the period of July $01-16$ of 2003 are listed in Table 3 . The fraction of variance explained by the CAM2 PC2 at SHMO is larger than that by the AIRS PC2 at same region by a factor of 2 , indicating an unrealistically large spatial variation of the stratospheric temperature simulated by CAM 2 over that region.

[49] The CAM2 PC1s and their spatial maps over the two regions (which are not shown here) have good agreement with their AIRS counterparts. The CAM2 PC2s and their spatial maps are shown in Figure 14. The spatial maps are in very good agreement with their AIRS counterparts (Figures 10a and 10c). To a large extent, the CAM2 PC2s are also in good agreement with the AIRS PC2s (Figures $9 \mathrm{~b}$ and 9d). The major discrepancies are (1) over the NHMO, the CAM2 PC2 (Figure 14a) shows a larger radiance change 

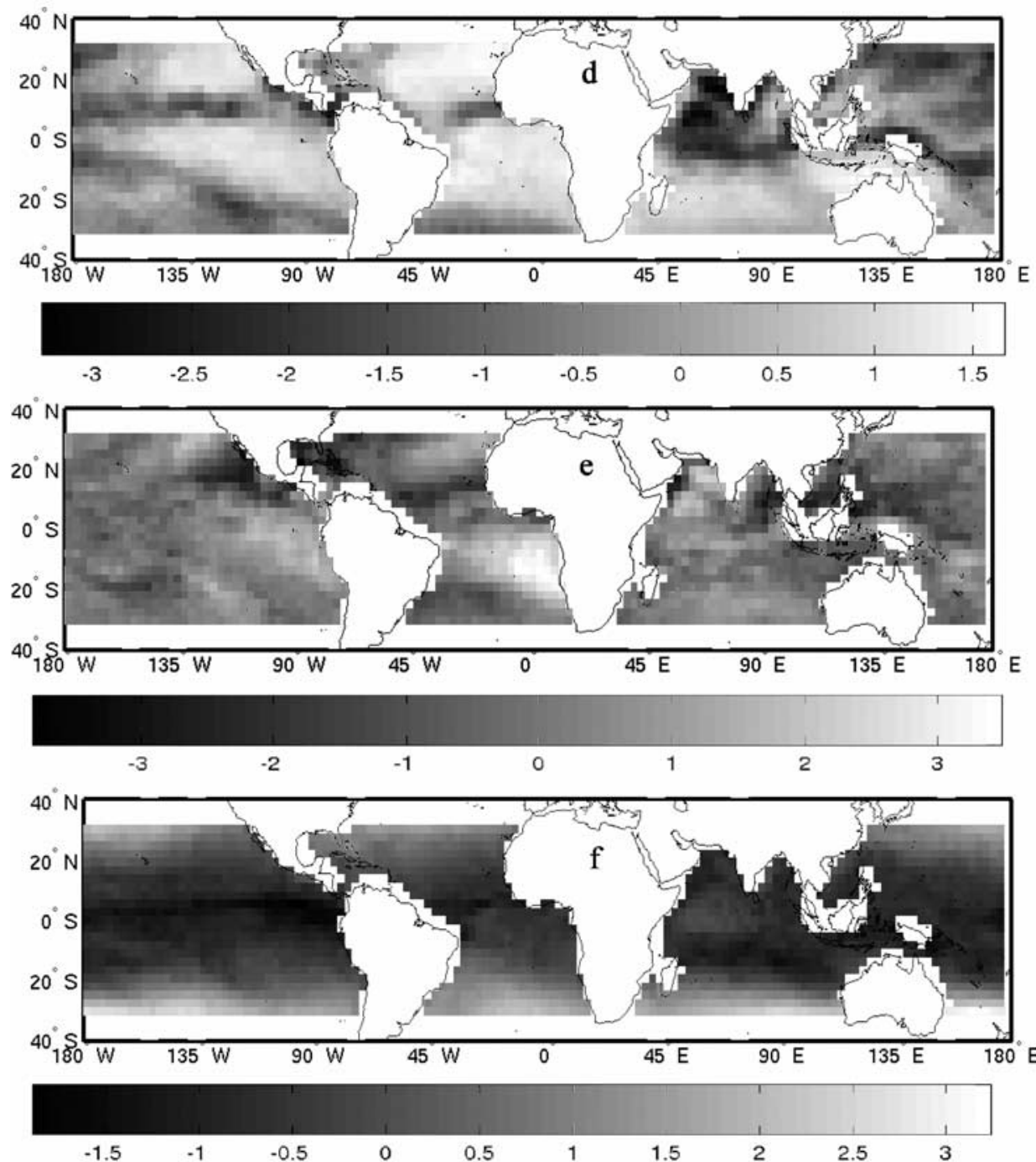

Figure 13. (continued)

at the $\mathrm{CO}_{2} 667 \mathrm{~cm}^{-1}$ band and smaller radiance changes at the weak water vapor absorption lines than AIRS PC2 (Figure 9b); (2) over the SHMO, the CAM2 PC2 (Figure 14c) shows a larger radiance change at the $\mathrm{CO}_{2}$ $667 \mathrm{~cm}^{-1}$ band than the AIRS PC2 (Figure 9d) by a factor of $\sim 2$. Both discrepancies disclose that the model has larger spatial variation of the midlatitude stratospheric temperature in both hemispheres than the reality.

[50] CAM2, as well as other GCMs, is designed to simulate the general circulation in the troposphere. The stratosphere in these GCMs is usually not as well represented as the troposphere. The top boundary of these GCMs is usually around the stratopause $(\sim 50 \mathrm{~km})$. Therefore, it is understandable that the stratosphere is not well simulated in such GCMs. But to what extent the unrealistic simulation of the stratosphere can be tolerated is still under debate. The stratosphere can affect the troposphere radiatively by changing the amount of solar flux that can reach the troposphere and the amount of downwelling longwave radiation emitted from the stratosphere [Forster et al., 1997; Hansen et al., 1997]. It can also affect the troposphere dynamically by downward propagation of zonal-mean anomalies, a mechanism known as the "downward control principle" [Haynes et al., 1991]. Recently observational [Ambaum and Hoskins, 2002; Baldwin and Dunkerton, 2001; Baldwin et al., 2003; Thompson et al., 2002] and modeling studies [Scott and Polvani, 2004; Shindell et al., 2001; Taguchi and Yoden, 2002] have demonstrated that the stratosphere is an active player in the tropospheric climate and weather. Given these facts, the discrepancies of CAM2 in simulating the spatial variations of the stratospheric temperature might be worthy of further investigation.

\section{Conclusion and Discussion}

[51] In this paper, we present a case study of the patterns of the spatial and spectral variability in the AIRS radiance data over the tropical/subtropical and the midlatitude oceans

Table 3. Fraction of Variance Explained by Three Leading CAM2 PCs Over Climate Zones Examined

\begin{tabular}{lccc}
\hline & PC1 & PC2 & PC3 \\
\hline Tropical/subtropical oceans & $98.9 \%$ & $0.5 \%$ & $0.3 \%$ \\
NHMO & $98.4 \%$ & $1.0 \%$ & $0.3 \%$ \\
SHMO & $96.1 \%$ & $3.6 \%$ & $0.2 \%$ \\
\hline
\end{tabular}



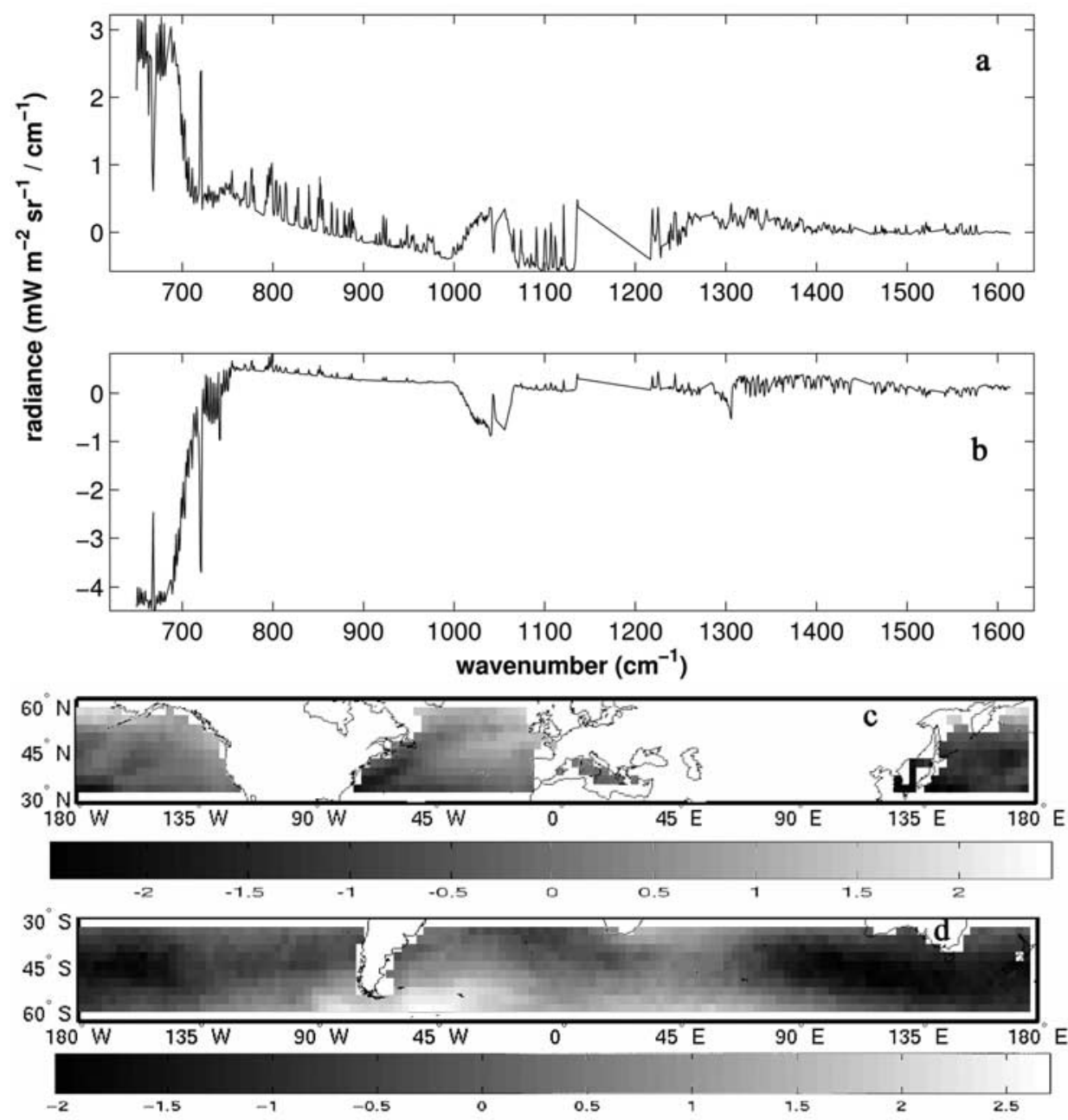

Figure 14. (a) The PC2 over the NHMO based on CAM2 simulation during July 1-16, 2003. (b) Same as Figure 14a for the SHMO. (c) The spatial map of the PC2 in Figure 14a. (d) Same as Figure 14c for the SHMO.

and a similar case study to synthetic spectra based on a CAM2 simulation, with focus on the boreal summer. Although the forced orthogonality of the EOFs makes the interpretation of the higher order PCs difficult, the three leading PCs over the tropical/subtropical oceans and the two leading PCs over the midlatitude oceans still have relatively simple interpretations. For all three climate zones examined, the PC1 is due to the contrast between surface temperatures and cold cloud top temperatures. The PC2s over the tropical/subtropical oceans and the summertime NHMO are mainly due to the spatial variation of the LTH and the low clouds and capture the variations in the stratosphere and the upper troposphere as well. The PC2s over the SHMO (both the wintertime and summertime) and the wintertime NHMO and the PC3 over the tropical/subtropical oceans are mainly due to the temperature variations in the upper troposphere and the lower stratosphere. The north-south contrast shown in the PC2s over the NHMO and the SHMO is mainly due to a relatively "quieter" summer troposphere in the southern hemisphere midlatitudes than in the northern hemisphere midlatitudes.
[52] The spectral EOF results based on CAM2 simulation over the same period show generally good agreement with AIRS results. The major discrepancies lie in the position of ITCZ over the western Pacific and the central Pacific, the underrepresented dust aerosol over the Arabian Sea and the Atlantic Coast off North Africa, and the overestimated spatial variations of the lower stratospheric temperature at midlatitudes. The close connection of the ITCZ with mesoscale tropical convective activities and air-sea interaction limits the capability of GCMs in the realistic simulation of the latitudinal preference of the ITCZ. The heavy load of dust aerosol in certain regions seen from the PC2 demands a more realistic treatment of dust aerosol in the GCMs. The consistent overestimation of the stratospheric temperature changes at the midlatitudes might also need further investigation given the potential influence of the stratosphere on the tropospheric climate and weather.

[53] The study presented here demonstrates that various meaningful results can be obtained by looking at a single data set, the outgoing thermal IR spectra. For example, our study shows that, over the southern hemisphere midlatitude 

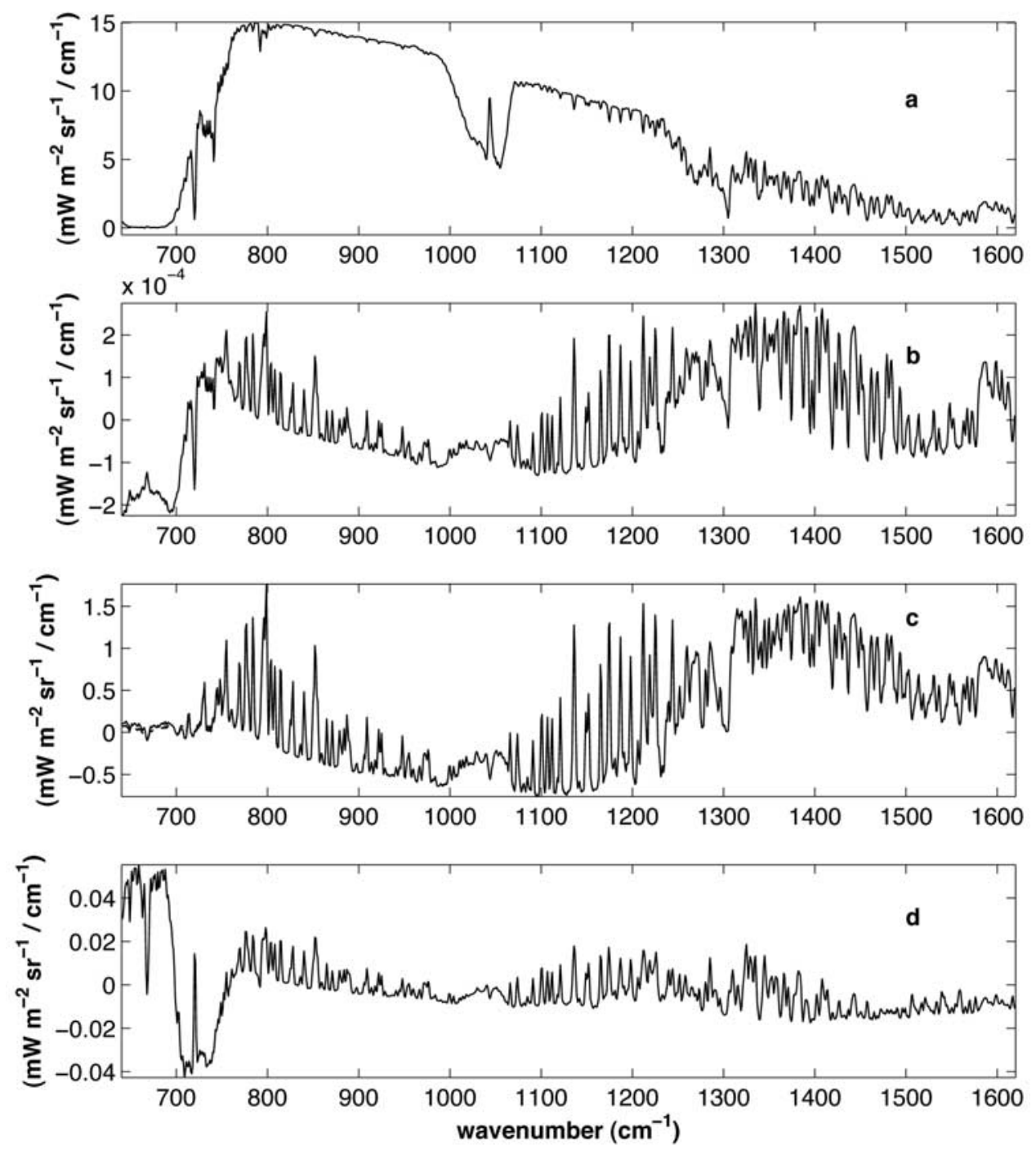

Figure A1. (a) The solid line is the PC1 (degraded to $2 \mathrm{~cm}^{-1}$ resolution) from EOF analysis to the original MODTRAN spectra, the case 1. The dashed line is the PC1 from the EOF analysis to the degraded MODTRAN spectra with $2 \mathrm{~cm}^{-1}$ resolution, the case 2. (b) The difference between the two PC1s in Figure A1a. Notice the difference is very small, only at $10^{-4} \mathrm{~mW} \mathrm{~m}^{-2} \mathrm{sr}^{-1} / \mathrm{cm}^{-1}$. (c) Same as Figure A1a for the PC2s. (d) Same as Figure A1b for the difference between the two PC2s. Note the order-of-magnitude difference in the y-axis between Figure A1a/Figure A1c and Figure A1b/Figure A1d.

oceans, almost all the spatial variability in the troposphere can be captured by the PC1 and lower stratospheric signal is dominant in the PC2. Over the northern hemisphere midlatitude oceans, the same conclusion holds in the winter period but not in the summer period. This inter-hemispheric asymmetry, which is useful in evaluating model performance, is readily seen from AIRS data but not from OLR or single-channel narrowband measurements because the decomposition of the spectra is necessary to obtain the primary variability (the $\mathrm{PC} 1$ ) and then the second variability (the PC2). It is conceivable that, combined with other data sets, it would have more potential in climate studies and climate model development. This year, CLOUDSAT and AURA will join AQUA (the carrier of AIRS) as well as several other satellites to form the A-train to observe clouds and other atmospheric variables [Stephens et al., 2002].
This new epoch of satellite observations will open a new era in climate studies and hasten the much-needed validation of climate models.

\section{Appendix A}

[54] The spectral resolution of AIRS data varies with the frequency $\left(\sim 0.5-1.3 \mathrm{~cm}^{-1}\right.$ for the spectral range of our interest), but the MODTRAN band model generates spectra at a $1 \mathrm{~cm}^{-1}$ interval. We conduct a sensitivity study to investigate the effect of the different spectral resolution on the spectral EOF analysis results. First, we use spectra generated by MODTRAN at a $1 \mathrm{~cm}^{-1}$ interval to do the EOF analysis (hereafter, case 1). Second, we degrade the spectra to $2 \mathrm{~cm}^{-1}$ resolution and apply the EOF analysis to these coarse-resolution spectra (hereafter, case 2). There is 
little difference between the EOF results from the two cases. If we degrade the PC1 from the case 1 to the same resolution as the spectra used in the case 2 and plot it with the PC1 from the case 2 (Figure A1a), they are almost not distinguishable. The difference between them (Figure A1b) is in the order of $10^{-4} \mathrm{~mW} \mathrm{~m}{ }^{-2} \mathrm{sr}^{-1} / \mathrm{cm}^{-1}$. The difference between the two PC2s is also tiny (Figure A1d). The differences in the spatial maps of the PCs and the fractions of variance explained by the PCs between the two cases are also small. Therefore, the different spectral resolutions between our synthetic spectra and the AIRS spectra should have little impact on the EOF analysis results.

[55] Acknowledgments. The AIRS data were obtained from GES Distributed Active Archive Center (http://daac.gsfc.nasa.gov/data/datapool/ AIRS DP/). The computer resources for CAM2 simulation were kindly provided by NCAR Scientific Computing Division. We wish to thank R. Goody, V. Ramaswamy, D. Noone, D. Schwarzkopf, J. W. Hurrell, M. Chahine, B. H. Lambrigtsen, and G. Aumann for valuable insights and help. We also thank three anonymous reviewers for improving the quality of this paper. This research was done when X. L. Huang was a graduate student at the California Institute of Technology and was supported in part by the AIRS project at JPL and NASA grant NAG1-1806 to the California Institute of Technology.

\section{References}

Ackerman, S. A. (1997), Remote sensing aerosols using satellite infrared observations, J. Geophys. Res., 102(D14), 17,069-17,079.

Ackerman, S. A., and S. K. Cox (1989), Surface weather observations of atmospheric dust over the southwest summer monsoon region, Meteorol. Atmos. Phys., 41(1), 19-34.

Ackerman, S. A., W. L. Smith, J. D. Spinhirne, and H. E. Revercomb (1990), The 27-28 October 1986 fire ifo cirrus case-study-Spectral properties of cirrus clouds in the 8-12 mu-m window, Mon. Weather Rev., 118(11), 2377-2388.

Ambaum, M. H. P., and B. J. Hoskins (2002), The NAO tropospherestratosphere connection, J. Clim., 15(14), 1969-1978.

Anderson, J. G., J. A. Dykema, R. M. Goody, H. Hu, and D. B. KirkDavidoff (2004), Absolute, spectrally resolved, thermal radiance: A benchmark for climate monitoring from space, J. Quant. Spectrosc. Radiat. Transfer, 85(3-4), 367-383.

Aumann, H. H., et al. (2003), AIRS/AMSU/HSB on the aqua mission: Design, science objectives, data products, and processing systems, IEEE Trans. Geosci. Remote Sens., 41(2), 253-264.

Baldwin, M. P., and T. J. Dunkerton (2001), Stratospheric harbingers of anomalous weather regimes, Science, 294(5542), 581-584.

Baldwin, M. P., D. B. Stephenson, D. W. J. Thompson, T. J. Dunkerton, A. J. Charlton, and A. O'Neill (2003), Stratospheric memory and skill of extended-range weather forecasts, Science, 301(5633), 636-640.

Bernstein, L. S., A. Berk, P. K. Acharya, D. C. Robertson, G. P. Anderson, J. H. Chetwynd, and L. M. Kimball (1996), Very narrow band model calculations of atmospheric fluxes and cooling rates, J. Atmos. Sci., 53(20), 2887-2904.

Bjerknes, J., L. J. Allison, E. R. Kreins, F. A. Godshall, and G. Warnecke (1969), Satellite mapping of Pacific tropical cloudiness, Bull. Am. Meteorol. Soc., 50(5), 313-322.

Carlson, T. N., and S. G. Benjamin (1980), Radiative heating rates for Saharan dust, J. Atmos. Sci., 37(1), 193-213.

Chahine, M. T. (1992), The hydrological cycle and its influence on climate, Nature, 359(6394), 373-380.

Chao, W. C. (2000), Multiple quasi equilibria of the ITCZ and the origin of monsoon onset, J. Atmos. Sci., 57(5), 641-651.

Chao, W. C., and B. D. Chen (2001), Multiple quasi equilibria of the ITCZ and the origin of monsoon onset. Part II: Rotational ITCZ attractors, J. Atmos. Sci., 58(18), 2820-2831.

Charney, J. G., and P. G. Drazin (1961), Propagation of planetary scale disturbances from the lower into the upper atmosphere, J. Geophys. Res., $66,83-109$.

Collins, W. D. (2001), Effects of enhanced shortwave absorption on coupled simulations of the tropical climate system, J. Clim., 14(6), 1147-1165.

Collins, W. D., J. K. Hackney, and D. P. Edwards (2002), An updated parameterization for infrared emission and absorption by water vapor in the National Center for Atmospheric Research Community Atmosphere Model, J. Geophys. Res., 107(D22), 4664, doi:10.1029/2001JD001365.
Collins, W. D., et al. (2003), Description of the NCAR Community Atmosphere Model (CAM2), 190 pp., Natl. Cent. for Atmos. Res., Boulder, Colo.

Crevoisier, C., S. Heilliette, A. Chédin, S. Serrar, R. Armante, and N. A. Scott (2004), Midtropospheric $\mathrm{CO}_{2}$ concentration retrieval from AIRS observations in the tropics, Geophys. Res. Lett., 31, L17106, doi:10.1029/2004GL020141.

Engelen, R. J., E. Andersson, F. Chevallier, A. Hollingsworth, M. Matricardi, A. P. McNally, J.-N. Thépaut, and P. D. Watts (2004), Estimating atmospheric $\mathrm{CO}_{2}$ from advanced infrared satellite radiances within an operational 4D-Var data assimilation system: Methodology and first results, J. Geophys. Res., 109, D19309, doi:10.1029/2004JD004777.

Fetzer, E., et al. (2003), Validation of AIRS/AMSU/HSB core products for data release version 3.0, JPL Internal Doc. D-26538, 79 pp., Jet Propul. Lab., Pasadena, Calif. (Available at http://daac.gsfc.nasa.gov/atmodyn/ airs/)

Forster, P. M. D., R. S. Freckleton, and K. P. Shine (1997), On aspects of the concept of radiative forcing, Clim. Dyn., 13(7-8), 547-560.

Gaiser, S. L., H. H. Aumann, L. L. Strow, S. E. Hannon, and M. Weiler (2003), In-flight spectral calibration of the atmospheric infrared sounder, IEEE Trans. Geosci. Remote Sens., 41(2), 287-297.

Goody, R., and Y. L. Yung (1989), Atmospheric Radiation: Theoretical Basis, 519 pp., Oxford Univ. Press, New York.

Goody, R., J. Anderson, and G. North (1998), Testing climate models: An approach, Bull. Am. Meteorol. Soc., 79(11), 2541-2549.

Goswami, B. N., J. Shukla, E. K. Schneider, and Y. C. Sud (1984), Study of the dynamics of the Intertropical Convergence Zone with a symmetric version of the Glas Climate Model, J. Atmos. Sci., 41(1), 5-19.

Hagan, D. E., C. R. Webster, C. B. Farmer, R. D. May, R. L. Herman, E. M. Weinstock, L. E. Christensen, L. R. Lait, and P. A. Newman (2004), Validating AIRS upper atmosphere water vapor retrievals using aircraft and balloon in situ measurements, Geophys. Res. Lett., 31, L21103, doi:10.1029/2004GL020302.

Han, Q. Y., W. B. Rossow, and A. A. Lacis (1994), Near-global survey of effective droplet radii in liquid water clouds using ISCCP data, J. Clim., 7(4), 465-497.

Hansen, J., M. Sato, and R. Ruedy (1997), Radiative forcing and climate response, J. Geophys. Res., 102(D6), 6831-6864.

Harries, J. E., H. E. Brindley, P. J. Sagoo, and R. J. Bantges (2001), Increases in greenhouse forcing inferred from the outgoing longwave radiation spectra of the Earth in 1970 and 1997, Nature, 410(6826), $355-357$.

Haskins, R., R. M. Goody, and L. Chen (1997), A statistical method for testing a general circulation model with spectrally resolved satellite data, J. Geophys. Res., 102(D14), 16,563-16,581.

Haskins, R., R. Goody, and L. Chen (1999), Radiance covariance and climate models, J. Clim., 12(5), 1409-1422.

Haynes, P. H., C. J. Marks, M. E. McIntyre, T. G. Shepherd, and K. P. Shine (1991), On the downward control of extratropical diabatic circulations by eddy-induced mean zonal forces, J. Atmos. Sci., 48(4), 651-679.

Herman, J. R., P. K. Bhartia, O. Torres, C. Hsu, C. Seftor, and E. Celarier (1997), Global distribution of UV-absorbing aerosols from Nimbus 7/ TOMS data, J. Geophys. Res., 102(D14), 16,911-16,922.

Hess, P. G., D. S. Battisti, and P. J. Rasch (1993), Maintenance of the Intertropical Convergence Zones and the large-scale tropical circulation on a water-covered Earth, J. Atmos. Sci., 50(5), 691-713.

Holton, J. R. (1983), The stratosphere and its links to the troposphere, in Large-Scale Dynamical Processes in the Atmosphere, edited by B. J. Hoskins and R. P. Pearce, 397 pp., Elsevier, New York.

Holton, J. T., J. M. Wallace, and J. A. Young (1971), Boundary layer dynamics and ITCZ, J. Atmos. Sci., 28(2), 27.

Hotelling, H. (1933), Analysis of a complex of statistical variables into principal components, J. Educ. Psychol., 24, 417-498.

Houze, R. A. (1993), Cloud Dynamics, 573 pp., Elsevier, New York.

Huang, X. L., R. Goody, Y. L. Yung, S. S. Leroy, and D. Crisp (2000), Spectrally resolved radiances from satellite and its application for climate signal detection, Eos Trans. $A G U, 81(48)$, Fall Meet. Suppl., Abstract A62B-21.

Huang, X. L., J. Farrara, S. S. Leroy, Y. L. Yung, and R. M. Goody (2002), Cloud variability as revealed in outgoing infrared spectra: Comparing model to observation with spectral EOF analysis, Geophys. Res. Lett., 29(8), 1270, doi:10.1029/2001GL014176.

Huang, X. L., J. J. Liu, and Y. L. Yung (2003), Analysis of thermal emission spectrometer data using spectral EOF and tri-spectral methods, Icarus, 165(2), 301-314

Husar, R. B., J. M. Prospero, and L. L. Stowe (1997), Characterization of tropospheric aerosols over the oceans with the NOAA advanced very high resolution radiometer optical thickness operational product, J. Geophys. Res., 102(D14), 16,889-16,909. 
Intergovernmental Panel on Climate Change (IPCC) (2001), Climate Change 2001: The Scientific Basis, edited by J. T. Houghton et al., Cambridge Univ. Press, New York.

Kalnay, E., et al. (1996), The NCEP/NCAR 40-year reanalysis project, Bull. Am. Meteorol. Soc., 77(3), 437-471.

Karyampudi, V. M., et al. (1999), Validation of the Saharan dust plume conceptual model using lidar, Meteosat, and ECMWF data, Bull. Am. Meteorol. Soc., 80(6), 1045-1075.

King, M. D., Y. J. Kaufman, W. P. Menzel, and D. Tanre (1992), Remotesensing of cloud, aerosol, and water-vapor properties from the Moderate Resolution Imaging Spectrometer (MODIS), IEEE Trans. Geosci. Remote Sens., 30(1), 2-27.

King, M. D., W. P. Menzel, Y. J. Kaufman, D. Tanre, B. C. Gao, S. Platnick, S. A. Ackerman, L. A. Remer, R. Pincus, and P. A. Hubanks (2003), Cloud and aerosol properties, precipitable water, and profiles of temperature and water vapor from MODIS, IEEE Trans. Geosci. Remote Sens. $41(2), 442-458$.

Klein, S. A., and D. L. Hartmann (1993), The seasonal cycle of low stratiform clouds, J. Clim., 6(8), 1587-1606.

$\mathrm{Li}, \mathrm{F}$., and V. Ramanathan (2002), Winter to summer monsoon variation of aerosol optical depth over the tropical Indian Ocean, J. Geophys. Res. 107(D16), 4284, doi:10.1029/2001JD000949.

Manabe, S., D. G. Hahn, and J. L. Holloway (1974), Seasonal-variation of tropical circulation as simulated by a global model of atmosphere, J. Atmos. Sci., 31(1), 43-83.

Middleton, N. J. (1986), Dust storms in the Middle-East, J. Arid Environ., $10(2), 83-96$

Mohalfi, S., H. S. Bedi, T. N. Krishnamurti, and S. D. Cocke (1998), Impact of shortwave radiative effects of dust aerosols on the summer season heat low over Saudi Arabia, Mon. Weather Rev., 126(12), $3153-3168$

Morcrette, J. J. (1991), Evaluation of model-generated cloudiness: Satelliteobserved and model-generated diurnal variability of brightness temperature, Mon. Weather Rev., 119(5), 1205-1224.

Pagano, T. S., H. H. Aumann, D. E. Hagan, and K. Overoye (2003), Prelaunch and in-flight radiometric calibration of the Atmospheric Infrared Sounder (AIRS), IEEE Trans. Geosci. Remote Sens., 41(2), $265-273$.

Prabhakara, C., R. S. Fraser, G. Dalu, M. L. C. Wu, R. J. Curran, and T. Styles (1988), Thin cirrus clouds-Seasonal distribution over oceans deduced from Nimbus-4 Iris, J. Appl. Meteorol., 27(4), 379-399.

Preisendorfer, R. W. (1988), Principal Component Analysis in Meteorology and Oceanography, 425 pp., Elsevier, New York.

Prospero, J. M., P. Ginoux, O. Torres, S. E. Nicholson, and T. E. Gill (2002), Environmental characterization of global sources of atmospheric soil dust identified with the Nimbus 7 Total Ozone Mapping Spectrometer (TOMS) absorbing aerosol product, Rev. Geophys., 40(1), 1002, doi:10.1029/2000RG000095.

Rasch, P. J., and J. E. Kristjansson (1998), A comparison of the CCM3 model climate using diagnosed and predicted condensate parameterizations, J. Clim., 11(7), 1587-1614.
Reynolds, R. W., and T. M. Smith (1994), Improved global sea-surface temperature analyses using optimum interpolation, J. Clim., 7(6), 929-948.

Rossow, W. B., and R. A. Schiffer (1999), Advances in understanding clouds from ISCCP, Bull. Am. Meteorol. Soc., 80(11), 2261-2287.

Schmetz, J., and L. Vandeberg (1994), Upper-tropospheric humidity observations from Meteosat compared with short-term forecast fields, Geophys. Res. Lett., 21(7), 573-576.

Scott, R. K., and L. M. Polvani (2004), Stratospheric control of upward wave flux near the tropopause, Geophys. Res. Lett., 31, L02115, doi:10.1029/2003GL017965.

Shindell, D. T., G. A. Schmidt, R. L. Miller, and D. Rind (2001), Northern Hemisphere winter climate response to greenhouse gas, ozone, solar, and volcanic forcing, J. Geophys. Res., 106(D7), 7193-7210.

Soden, B. J., and F. P. Bretherton (1994), Evaluation of water-vapor distribution in General-Circulation Models using satellite-observations, J. Geophys. Res., 99(D1), 1187-1210.

Stephens, G. L., et al. (2002), The Cloudsat mission and the A-train-A new dimension of space-based observations of clouds and precipitation, Bull. Am. Meteorol. Soc., 83(12), 1771-1790.

Taguchi, M., and S. Yoden (2002), Internal interannual variability of the troposphere- stratosphere coupled system in a simple global circulation model. Part I: Parameter sweep experiment, J. Atmos. Sci., 59(21), $3021-3036$

Thompson, D. W. J., M. P. Baldwin, and J. M. Wallace (2002), Stratospheric connection to Northern Hemisphere wintertime weather: Implications for prediction, J. Clim., 15(12), 1421-1428.

Tindale, N. W., and P. P. Pease (1999), Aerosols over the Arabian Sea: Atmospheric transport pathways and concentrations of dust and sea salt, Deep Sea Res., Part II, 46(8-9), 1577-1595.

Waliser, D. E., and C. Gautier (1993), A satellite-derived climatology of the ITCZ, J. Clim., 6(11), 2162-2174.

Waliser, D. E., and R. C. J. Somerville (1994), Preferred latitudes of the Intertropical Convergence Zone, J. Atmos. Sci., 51(12), 1619-1639.

Wang, J. X., G. P. Anderson, H. E. Revercomb, and R. O. Knuteson (1996), Validation of FASCOD3 and MODTRAN3: Comparison of model calculations with ground-based and airborne interferometer observations under clear-sky conditions, Appl. Opt., 35(30), 6028-6040.

Wilber, A. C., D. P. Kratz, and S. K. Gupta (1999), Surface emissivity maps for use in satellite retrievals of longwave radiation, NASA Tech. Publ., TP-1999-209362, $35 \mathrm{pp}$.

Zhang, M. H., W. Y. Lin, C. S. Bretherton, J. J. Hack, and P. J. Rasch (2003), A modified formulation of fractional stratiform condensation rate in the NCAR Community Atmospheric Model (CAM2), J. Geophys. Res., 108(D1), 4035, doi:10.1029/2002JD002523.

X. Huang, Program in Atmospheric and Oceanic Sciences, Princeton University, 300 Forrestal Road, Sayre Hall, P.O. Box CN710, Princeton, NJ 08544-0710, USA. (xianglei.huang@noaa.gov)

Y. L. Yung, Division of Geological and Planetary Sciences, California Institute of Technology, Mail Stop 150-21, Pasadena, CA 91125, USA 

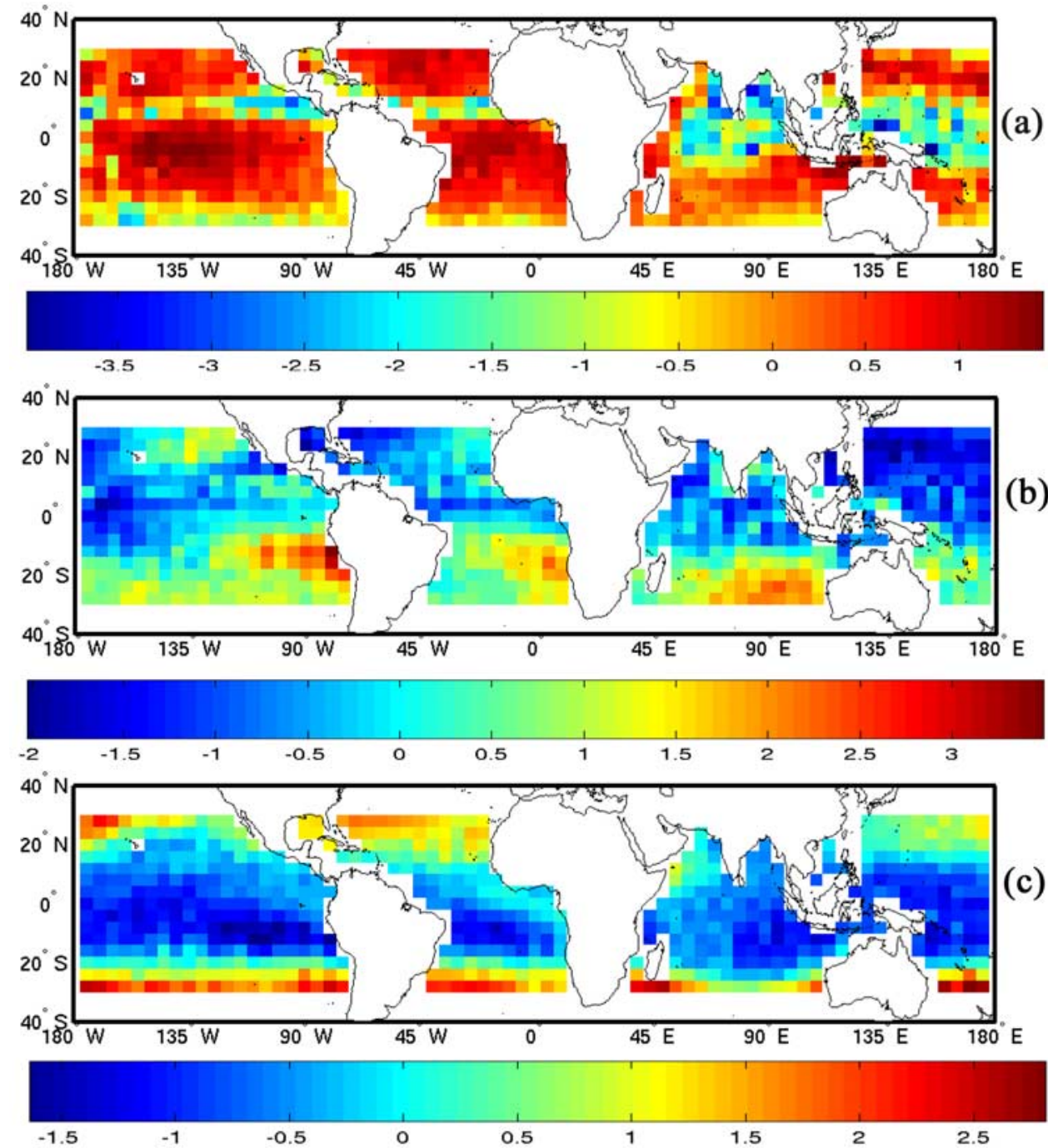

Figure 4. (a) The spatial map of the PC1 shown in Figure 3a. In other words, it is the normalized expansion coefficient of the PC1 computed based on equation (3) in the context. (b) The spatial map of the PC2 shown in Figure 3b. (c) The spatial map of the PC3 shown in Figure 3c. 

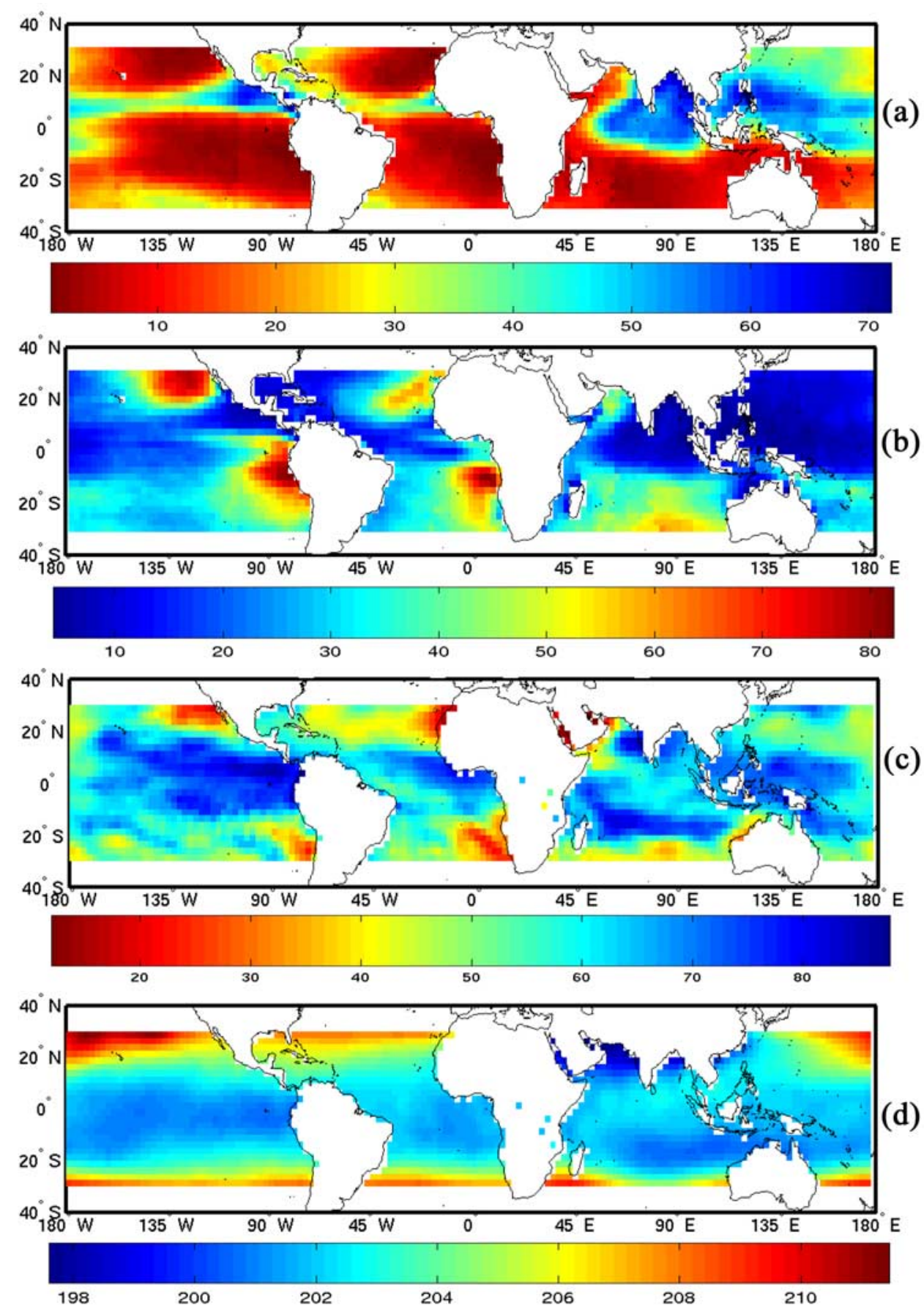

Figure 5. (a) The climatological high cloud amount (in percentage) in July from ISCCP D2 data set. (b) The climatological low cloud amount (in percentage) in July from ISCCP D2 data set. (c) The $850 \mathrm{mb}$ relative humidity (in percentage) averaged over July 1-16, 2003, from NCEP daily reanalysis product. (d) The temperature (in $\mathrm{K}$ ) in the layer of $150 \mathrm{mb}-70 \mathrm{mb}$ averaged over July $1-16,2003$, also from NCEP. 

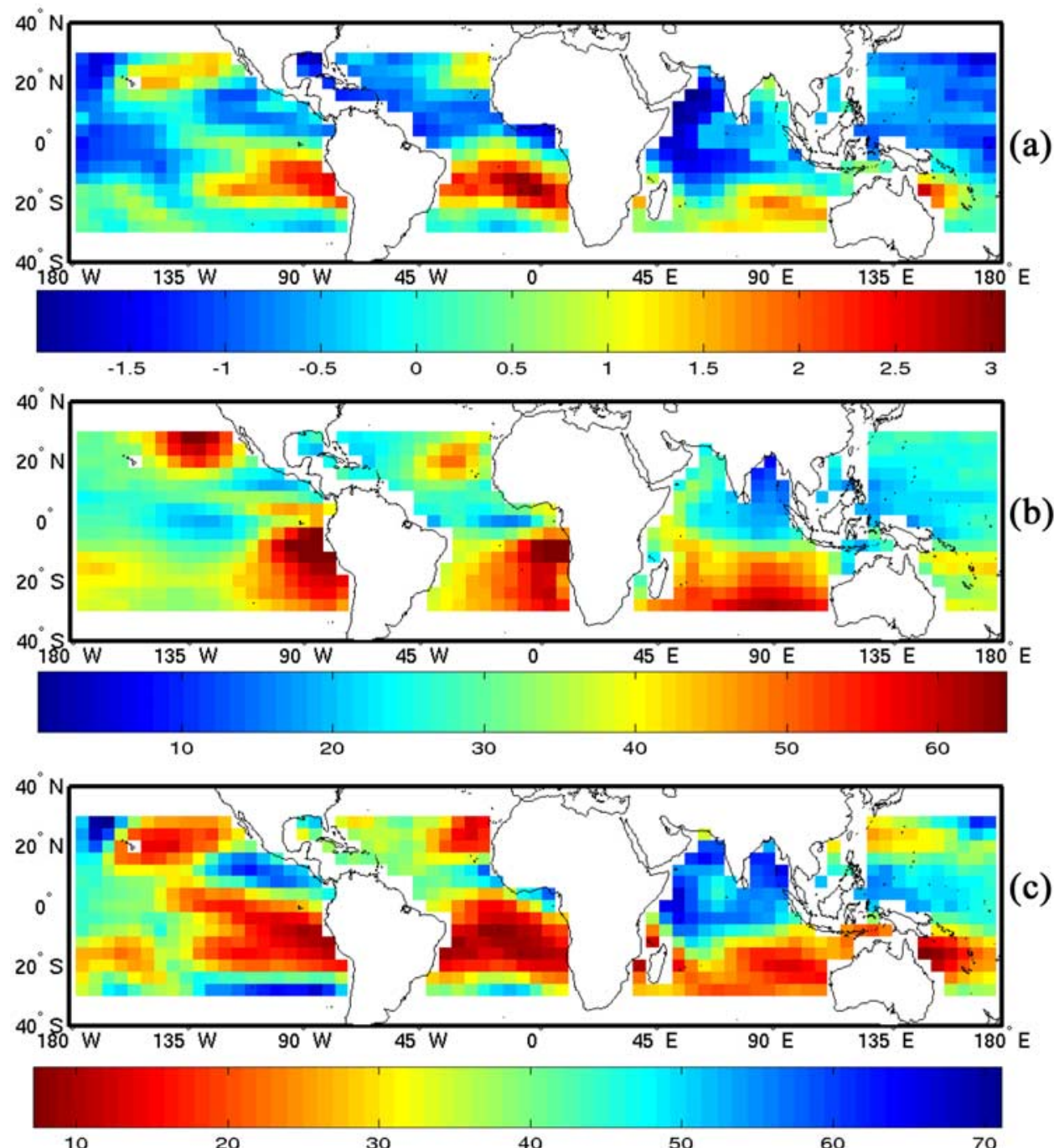

Figure 7. (a) The PC2 spatial map of the simulated NCEP + ISCCP cloudy case. Refer to the context for the definitions of the ISCCP cloudy case. (b) The ISCCP climatological low cloud amount (in percentage) used in the simulation. It is identical to Figure $5 \mathrm{~b}$ except that it has been smoothed to $4^{\circ}$ latitude by $5^{\circ}$ longitude resolution. (c) The NCEP relative humidity (in percentage) of 300-500 mb layer averaged over July $1-16,2003$, smoothed to $4^{\circ}$ latitude by $5^{\circ}$ longitude resolution. 

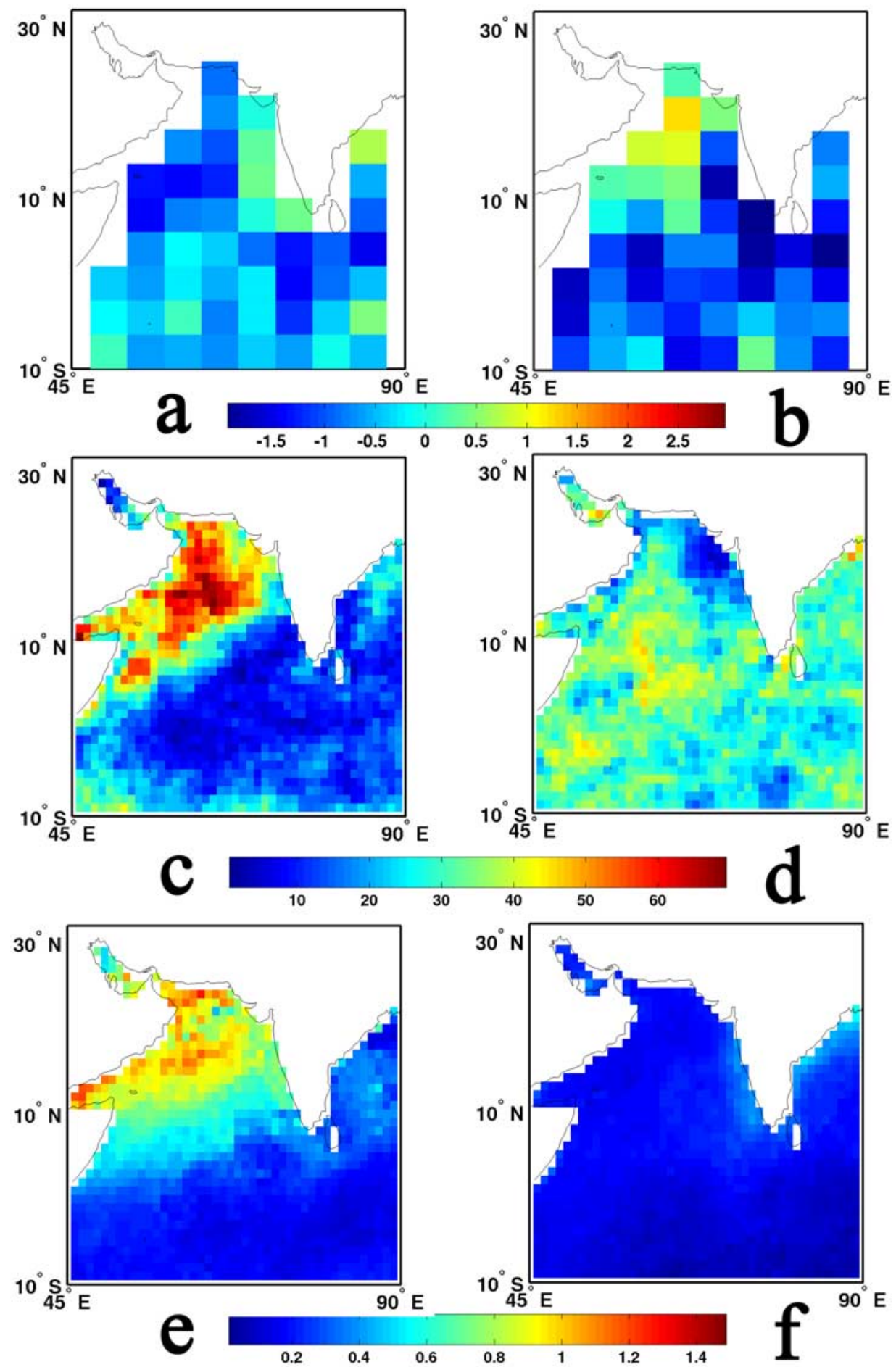

Figure 8. (a) The PC2 over the Arabian Sea derived from AIRS data over July 1-16, 2003. (b) Same as Figure 8a for January 1-16, 2003. (c) The monthly mean low cloud amount of July 2003 derived from MODIS observation. (d) Same as Figure 8c for January 2003. (e) The monthly mean aerosol optical depth of July 2003 derived from MODIS observation. (f) Same as Figure 8e for January 2003. 

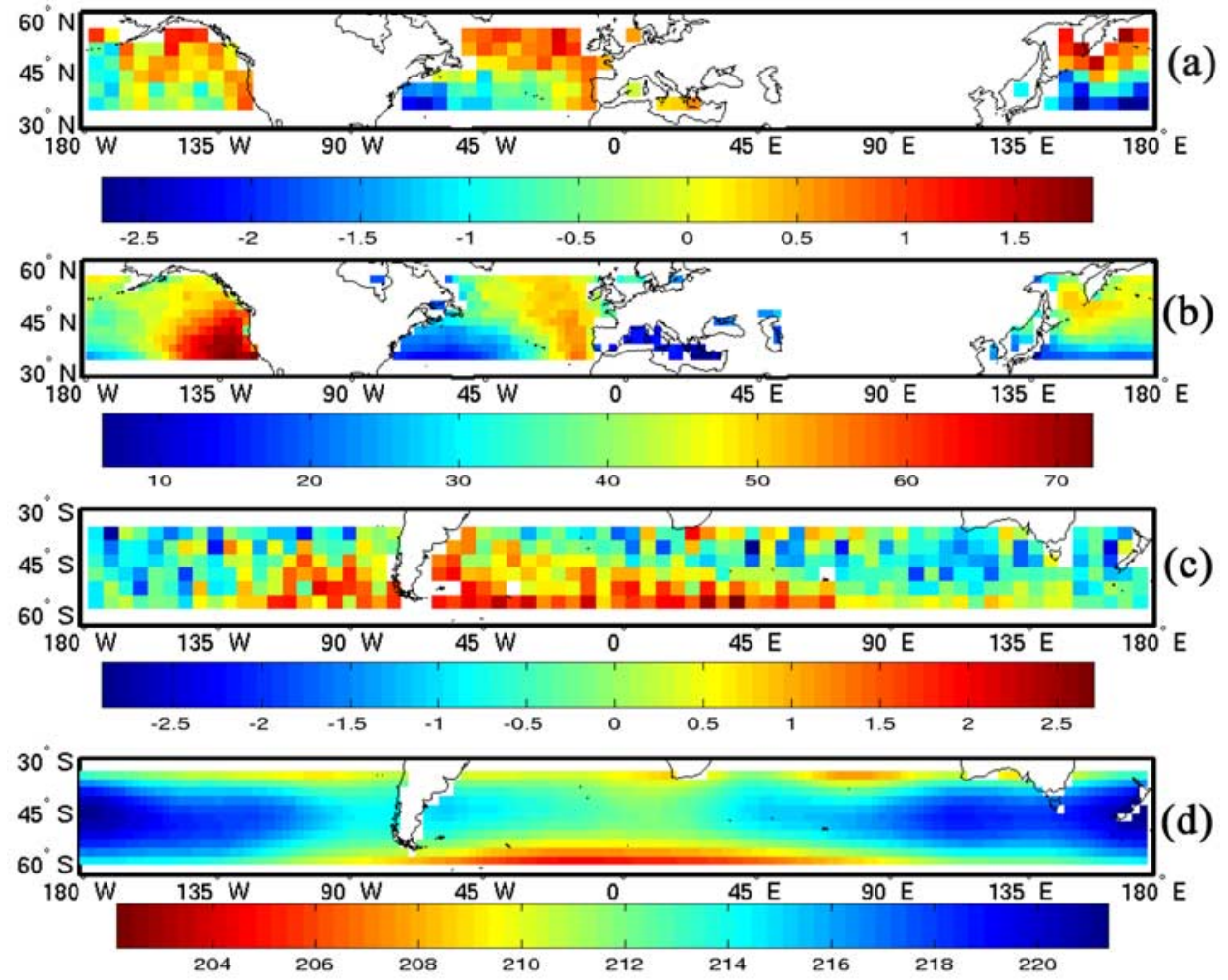

Figure 10. (a) The PC2 spatial map over the NHMO. (b) The ISCCP climatological low cloud amount of July over the same regions as Figure 10a. (c) The PC2 spatial map over SHMO. (d) The NCEP 16-day (July $1-16,2003$ ) average of $100 \mathrm{mb}$ temperature over the same regions as Figure 10c. 